\title{
Usability evaluation model of an application with emphasis on collaborative security: an approach from social dimensions
}

\author{
Mateus de Oliveira', Adriana Prest Mattedi ${ }^{2}$ and Rodrigo Duarte Seabra ${ }^{2^{*}}$ (D)
}

\author{
*Correspondence: rodrigo@unifei. \\ edu.br \\ This work was invited and is based \\ on an earlier one entitled Social \\ Dimensions in the Acceptance of \\ and Access to Technology: a \\ Usability Study in a Collaborative \\ Security Application published in \\ the Proceedings of the XVIII \\ Brazilian Symposium on Human \\ Factors in Computing Systems (IHC) \\ in 2019. \\ ${ }^{2}$ Institute of Mathematics and \\ Computing, Federal University of \\ Itajubá, Itajubá, MG, Brazil \\ Full list of author information is \\ available at the end of the article
}

\begin{abstract}
Technological ubiquity and advances in the use of networked devices, such as smartphones, have become a fundamental element in the dynamics of information in the social environment. Social problems can be discussed in these networks, receiving the aid from these devices, in order to unite community members in a network that is strengthened for common goals, transforming the local reality. The motivation for this work lies in the fact that lack of security is one of the problems that have most afflicted Brazilians in recent years. From this reality, the main objective of this study was the development of a usability analysis model suitable for smartphone applications and that allows identifying of the viability of using a collaborative security application in the social context of a city of the State of Minas Gerais, Brazil. The objective was designed to investigate how the different dimensions inherent to the social context interfere with the acceptance of technological resources, specifically, of a smartphone application in a community. Data collection was performed by applying two questionnaires to 22 participants living in the municipality (eight men and 14 women), one being a demographic survey and the other to evaluate usability focusing on users' perception of the use of the application. The application usage scenario is family safety facing the challenges of mitigating public security issues. The analysis of the results was based on the reinterpretation of usability from the perspective of the Theory of Innovation Diffusion and the Recursive Model of Access to Technology. In order to validate the reliability of the instrument used to collect the data regarding the usability of the application, Cronbach's alpha coefficient was applied. The result indicates that the instrument used was concise and efficient. The study enabled conclusions pointing that this type of interpretation allows us to glimpse at horizons that go beyond explicit aspects of usability, helping to understand environmental and social factors intrinsic to the context of technological diffusion in a developing society.
\end{abstract}

Keywords: Usability, Innovation diffusion, Access to technology, Social factors 


\section{Introduction}

The world has been evolving rapidly in the area of computing, especially in relation to information and communication technologies (ICTs), whereby the social scenario is transformed by several important historical events [1]. The use of software and websites that promote interactions between individuals, groups, and dynamic social networking, as well as the widespread use of Internet-connected devices, are increasingly bringing virtual social networks closer to real ones [2]. The formation of social networks, according to Rand et al. [3], ensures the maintenance of cooperativism, which is the central point for the success of human societies. These networks structure human relationships, which are dynamic and change each time an individual breaks or creates connections with others. The dynamics of these ties profoundly alter the network and thus allow cooperativism to be maintained or strengthened. Moreover, Elger [4] states that the "technosocial networks" allow constructing new possibilities for action to change public policies, in which individuals act directly on their objects of interest. Thus, its relations with the state are redefined in terms of the formulation of public policies and their effectiveness, the democratic participation of municipal management and the implications of daily life, given by urban reconfiguration. For example, the average daily active user in June 2018 on the Facebook site was 1.47 billion [5]. According to the Statista website [6], over 95\% of these users use smartphones as their access device and in the last quarter of 2017, Whatsapp averaged 60 billion messages daily [7].

Increasingly, human-computer interaction ( $\mathrm{HCI}$ studies tend to analyze not only the individual's relationship with the computer but move toward understanding how people interact with one another online [8], given the scope and effect caused by such widespread access to networks. Since ICTs are expanding in developing countries, HCI cannot be complete without studies of interactive systems in these regions [9]. According to Ho et al. [9], studies on "development informatics," "social implications of computers in developing countries," "Information Technologies and International Development," and "ICTs and development" culminated in an area of study that investigates how interactive products, applications, and systems can be adapted to the needs of users that live in developing regions to reduce the existing infrastructure difficulties in these regions. For the authors, the result of these studies may be called human-computer interaction for development (HCI4D). The HCI4D area seeks to understand how computational technologies can contribute to the socioeconomic development of economically impoverished communities and/or to solve a specific social or cultural challenge [9-11].

Violence is among the five issues that most concern Brazilians, according to a survey conducted by Datafolha in September 2018 [12]. Violence can alter the daily lives of people everywhere, causing loss of quality of life as it inhibits citizens' freedom of movement and social interaction [13]. Collaborative self-organization has been one of the solutions found by communities to address this problem, as is the case in other areas, for example in healthcare [14]. Collaborative actions by members of a community partnership produce changes in programs, policies, and practices across the community, reshaping their own agencies and organizations, and enabling a better approach to addressing relevant community issues [15]. Currently, there are security applications that can be used in the context aforementioned. Specifically for the security area, the following mobile 
applications can be highlighted: Alerta Digital (https://play.google.com/store/apps/ details?id=com.laperlita.commisur\&hl=es_419), Life360 (https://play.google.com/store/apps/ details?id=com.life360.android.safetymapd), Agentto (https://play.google.com/store/apps/ details?id=agentto.application), ProtectMe (https://play.google.com/store/apps/details?id= com.rocketmbsoft.protectme.advanced), CityCop (http://www.citycop.org/), and e Haus (https://haus-app.com/\#/index). The scenario of this work involves a personal safety app for smartphones.

Based on the above, the research question of this study is how do the different dimensions inherent in the social context interfere with the acceptance of technological resources, specifically, of a smartphone application in a community?

Thus, the research goal is to understand the influence of social dimensions on the process of acceptance and access to technology through a usability study for collaborative security applications. The analysis tool adds usability to the Innovation Diffusion Theory alongside the digital technology access model to explain participants' perceptions of the application and its social dimensions. In this paper, the perception concept adopted is the way in which individuals order and interpret their sensory impressions regarding facts, objects and people in order to understand their surroundings [16].

This work consists of an extended version of the research published in the Proceedings of the XVIII Brazilian Symposium on Human Factors in Computing Systems (IHC) in 2019 [17]. The new contribution of this paper in relation to the other one is related to the validation of the proposed usability model. First, Pearson's correlation was applied to verify the interrelationship between the questions. Subsequently, to validate the reliability and consistency of the questions, Cronbach's alpha was used globally and also at the individual levels presented in the model, achieving a promising result.

The following sections present the theoretical foundation (the "Theoretical concepts" section), which contains the concepts of diffusion and adoption of innovation, access to technology, and usability addressed in this study (the "Usability, adhesion, and access theoretical discussion" section). Then, the method and construction of the analytical model are described (the "Method" section), followed by the analysis of the results (the "Discussion of results" section). Finally, the final considerations are made.

\section{Theoretical concepts}

The process of adopting a new technology is not always clear. At the corporate level, for example, the inconsistency between high investment in information technology and its return on productivity was noticed due to low adoption and underutilization of deployed resources [18]. In order to provide support to these problems, several researchers have developed theories about technology adoption processes beginning in the 1970s. Among the most widespread theories in academia are the Theory of Rational Action [19], the Theory of Planned Behavior [20], the Technology Acceptance Model [21-23], the E-commerce Acceptance Model [24], the Unified Theory of Acceptance and Use of Technology [25], and the Diffusion of Innovation Theory [26].

Analysis of the different approaches to technology acceptance and diffusion reveals that there are constructs that are theoretically related to each other. Despite having distinct nomenclatures, the constructs deal with the same elements of human perception about technology. For example, the "Subjective Standard" presented in Technology 
Acceptance Models is equivalent to some extent to the "Nature of the Social System" present in the Innovation Diffusion Theory. Thus, the Theory of Innovation Diffusion [26] was used herein because it presents the concept of information diffusion in a social environment and explains a definition of the different profiles of technology adopters.

\section{Innovation Diffusion Theory and technology access model}

The Innovation Diffusion Theory presents a concept based on communication and considers the phenomenon of innovation diffusion along the adherence process to new technologies. For Rogers [26], a publication is a process of disseminating new literature. In turn, access to this information can reduce an individual's degree of uncertainty or risk perception regarding innovation. Diffusion is thus the process by which an innovation is communicated through certain channels over time between certain elements of a social system. The author highlights the importance of the social system and communication channels, since social, and communication structures interfere with the diffusion of an innovation. Figure 1 shows the diffusion cycle of innovations over time in relation to adopters.

Communication channels represent the means by which information is transmitted from one agent to another. In this process, the opinion leader appears as an influencing agent within the social system. The author argues that there is a temporal sequence of new technology adoption. It starts with the innovators, followed by the early adopters, then the early majority; after this, the late majority and, finally, the late adopters, the last to adhere to an innovation.

In the process of innovation diffusion, five factors influence the innovation adherence rate, namely perceived attributes of innovation; type of innovation decision; communication channels; nature of the social system; and extension efforts to promote change agents (Fig. 2). The adoption rate is the relative speed with which an innovation is adopted by members of a social system.

According to Rogers [26], the perceived attributes of innovation factor has the following constructs: relative advantage is the degree to which an innovation is perceived to be better than its precursor; compatibility refers to the degree to which an innovation

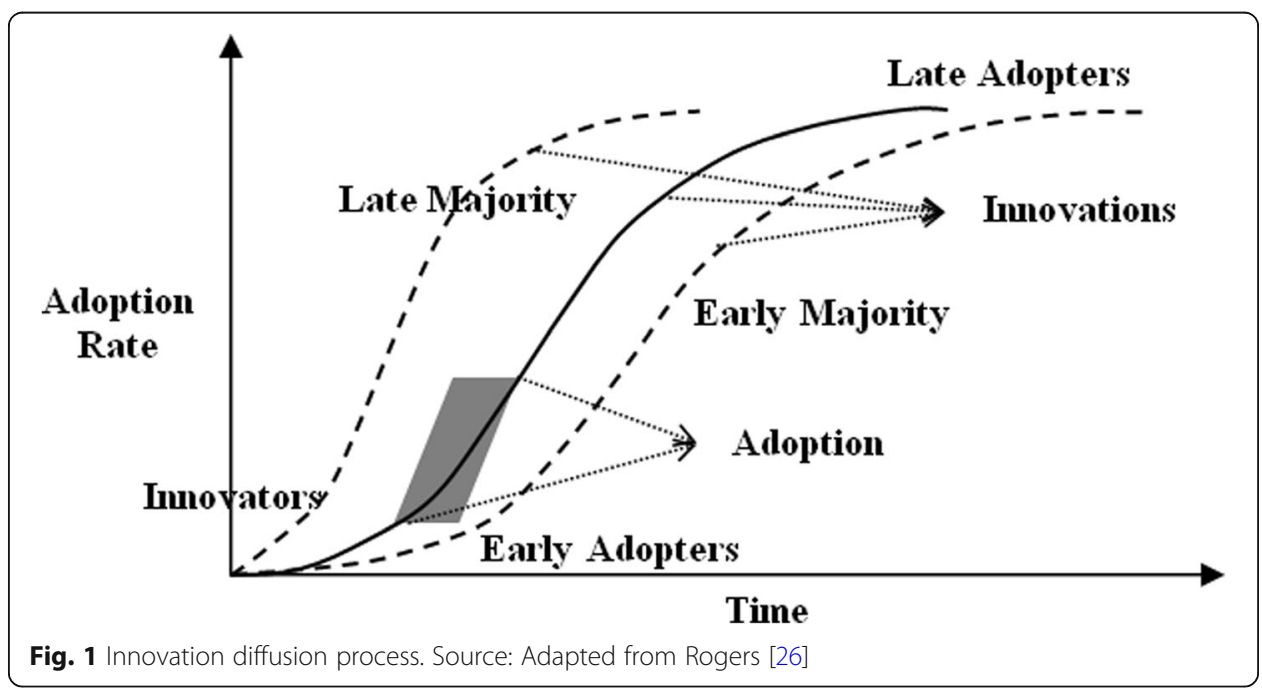




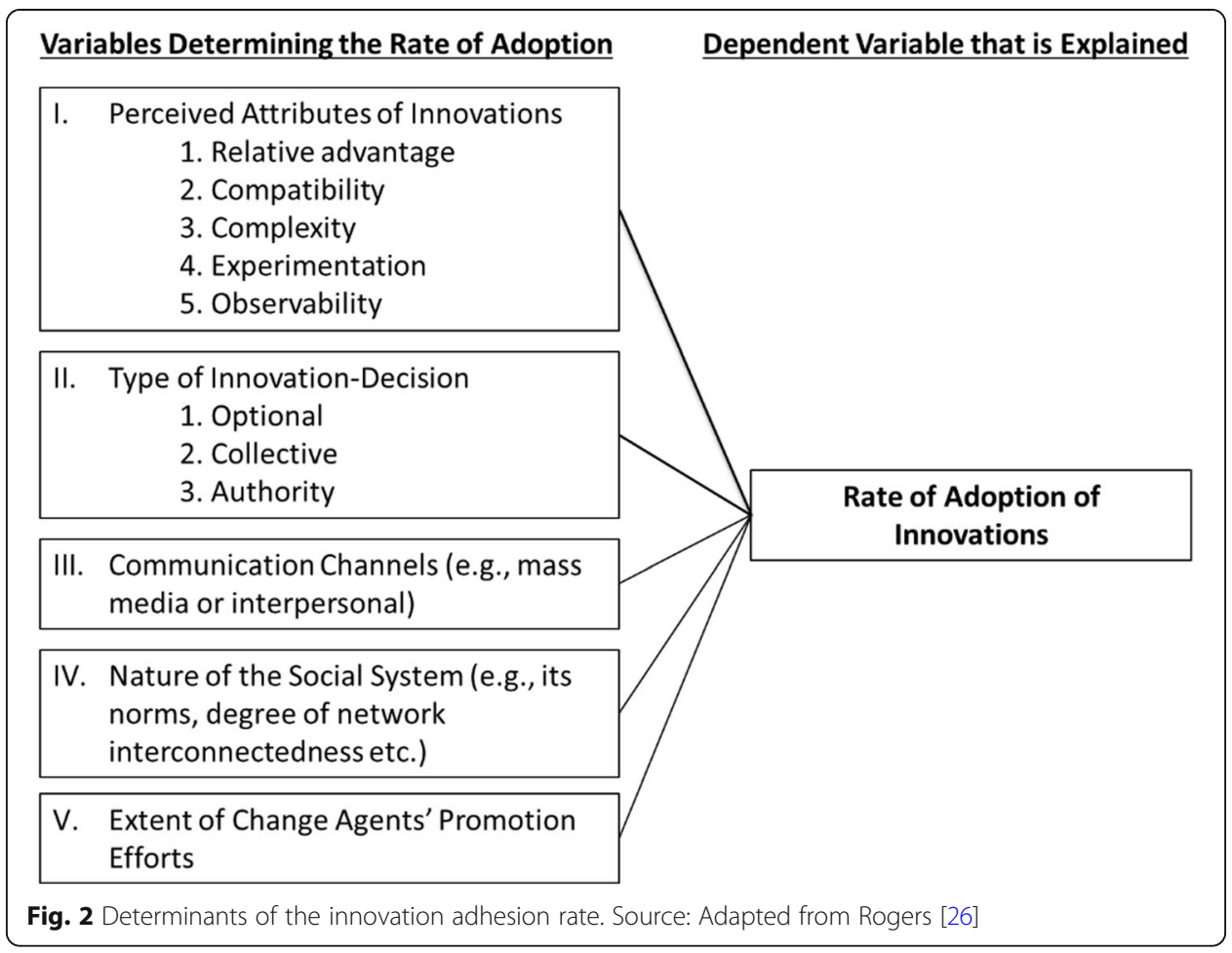

is perceived to be consistent with existing values, needs, and experiences of potential adopters; complexity is the relative degree to which innovation is observed as difficult to understand and use; observability is the degree to which the results of an innovation are observable by others; and, finally, experimentation is the degree to which an innovation can be tried on a limited basis.

Regarding the social system and channels of communication factors, the former consists of "a group of interconnected individuals involved in joint problem solving to achieve a goal" and the latter are the means by which a message it is transmitted from one social agent to another, whether through interpersonal relationships or through mass media [26]. Finally, there are studies that investigate the influence of the decision type on whether or not to use an innovation, which varies according to its nature (voluntary, collective, or authoritarian) and explains that the "Extension of Change Agent Promotion Effort" affects the adherence rate, although this relationship is generally not straightforward [26].

The perceived attributes of innovation factor is more emphasized herein, because the analysis model we propose makes it impossible to deepen the characteristics of the other factors. It is worth highlighting that studies related to demographics and other access factors provide more insights about the Rogers social system nature factor, especially in developing countries. In this case, the infrastructure is usually precarious, which makes the inclusion of these access models relevant to this study. Thus, considering the issue of access to technology is pertinent.

The access model addressed here considers mainly the capacity that users have for using digital technologies. Thereby, the cumulative recursive digital technology access model was the model used. Van Dijk [27] points out that access assessment must 
consider the social, cultural, and psychological context. The model presented in Fig. 3 describes the necessary steps for the technological appropriation to be realized.

This model describes that, prior to material access, the individual must be motivated to use a technology (motivational access). Lack of usefulness and need perception, financial resources scarcity, or even considering the technology as unskillful are some reasons of nonexistence of motivational access. Technical and material access refers to physical means of access to technology. After the first two stages, there is a chain of three skills (skill access) that rank the technology utilization degree. The lowest degree, called instrumental ability, describes the ability to work with hardware and software. The second degree refers to informational skill, which qualifies the ability to search, select, and process information on networks. The third degree, strategic skill, means the ability to use technologies to achieve personal goals and to enhance one's social position. Finally, the last level of the model, called usage access, can be measured by time, application, diversity, connection bandwidth, and intensity of active and/or creative internet use.

\section{Usability considerations}

Usability can be defined as "the ability of the software product to be understood, learned, operated, and be attractive to the user when used under specified conditions" [28]. In other words, usability assesses the ease of learning to use the system, the use efficiency, and the ability of the system to communicate with the user [29]. This encompasses improving user interactions with interactive products that enable them to perform their daily activities [30]. In addition, system functionality also affects usability, that is, the way elements present themselves and interact with user responses alters their perceptions [31].

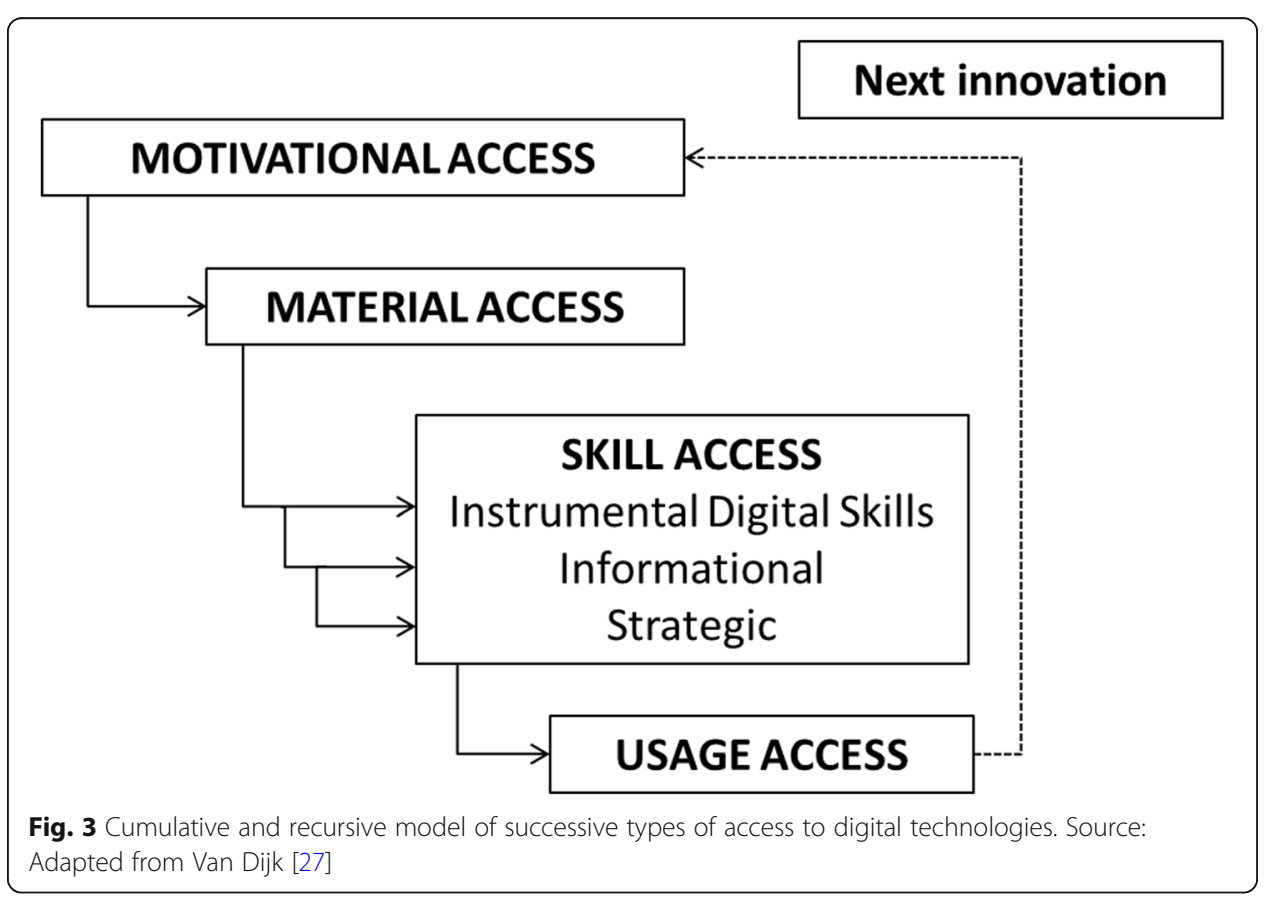


Usability is a term referring to a range of methods that evaluate user interaction with product and system interfaces. Usability-related literature often uses terms such as user-centered design (UCD), HCI, or user experience (UX), addressing design processes in which end users influence project progress [32]. These concepts reveal in their own names that, far beyond the software functional characteristics, it is important to think about the design building processes from the end user's view. In the past, these concepts were worked out in a scattered manner, although they addressed similar objectives.

Among the most widespread usability standards is ISO 9241-11, which defines usability and explains how to identify the information needed to specify or evaluate the usability of a visual interface in terms of performance measures and user satisfaction [33].

During the development of this research, ISO 9241-11 of 1998 was used. However, there is a more recent revision of 2018 that includes several new approaches and definitions, such as user-experience, which means user perception, including emotions, beliefs, preferences, perceptions, comfort, behaviors, and achievements, related to the system, product, or service that can occurs before, during, and after use. Even so, the constructs used in the model preserve the same fundamental characteristics [34].

In the 1980s, usability was commonly referred to as user-friendly. To consolidate existing theories at the time, Nielsen [35] converged these and other related terms into one-usability. Nielsen states that acceptability is one of the factors that indicate whether the system is good enough to meet user needs and requirements. In this context, the author describes the social and practical acceptances of a system, emphasizing, in the second, the potential of the system to be useful, which can still be understood by utility and usability, as illustrated in Fig. 4.

The model elements are Learning, Efficient Use, Easy to Remember, Errors, and Satisfaction. Learning is how easy it is for users to perform basic tasks the first time they use the product. Efficient Use is the speed at which users perform tasks once they know the interface. Memorization is how easy it is for users, after a certain time without using the product, to restore their proficiency in use. Errors refer to the number and severity of errors made by users compared to the users' ease of recovering from errors. Finally, Satisfaction points out how enjoyable it is to use the product.

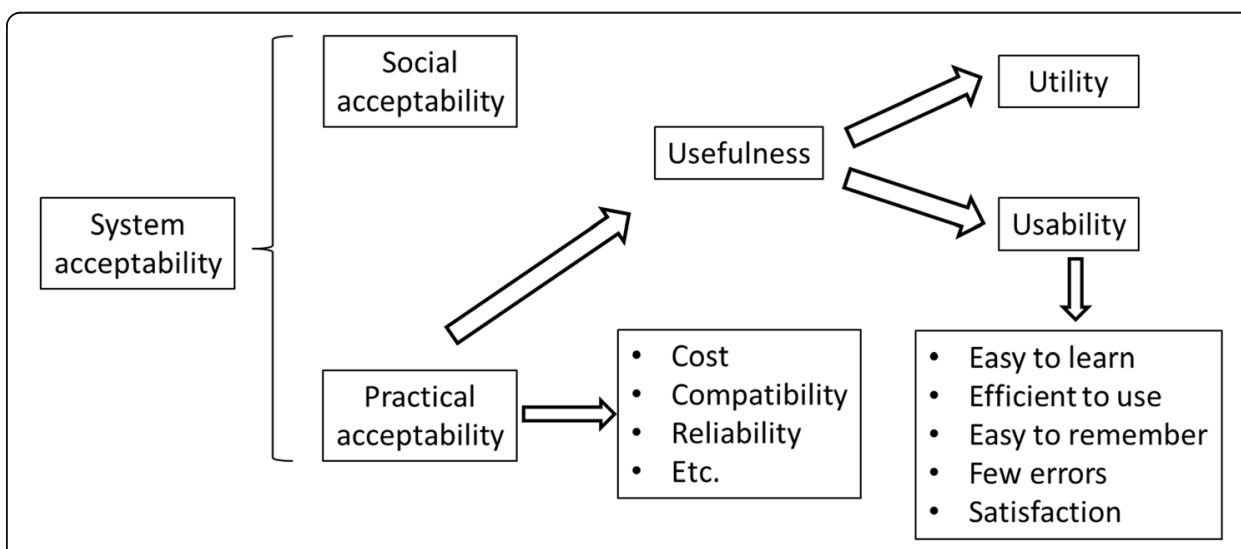

Fig. 4 Acceptability system attribute model. Source: adapted from Nielsen [35] 
With regard to the usability of mobile devices, in the past, the challenges are also reflected in their physical limitations and rapid changes in standards and technologies, i.e., limited screen size, content presentation, limited processing power, and data storage are some of them [36-38]. However, mobile devices have increased their screen size, memory and processing power. In the last decade, usability mobile applications have increased enormously as did the challenges in relation to quality. In this way, the continuous improvement of the structures is moving toward quality assurance [39]. In addition, there is the difficulty in developing pleasant graphical interfaces with succinct and intuitive content, which can be considered a consequence of the large number of application user evasions, that is, applications are installed and used a few times and soon end their life cycle.

Among different usability evaluation models in the literature, we here use the PostStudy System Usability Questionnaire (PSSUQ). This questionnaire assesses the satisfaction of computer system users and it was based on the psychometrics concept, which analyzes mental and behavioral models of people facing certain tasks [40]. It evaluates relevant usability aspects in everyday environments and presents 19 questions under three different dimensions: system utility (1-8), information quality (9-15), and interface quality (16-18). The last question involves the user's perception of the whole system.

\section{Related work}

In the technological acceptance field, one can mention Pavlou [24], who investigated the effective transactions rate in e-commerce, starting from an adaptation of the TRA model. As a result, risk perception and trust were found to be key attributes for the successful completion of a transaction and trust is a subjective attribute that precedes ease of use and perceived utility. However, this approach is very specific and its context differs from the goals of this research, although the author's interpretation about users' perceptions can clarify and enrich this study.

Regarding access to technology, Heeks [41] analyzed the possible causes of the high failure rate in the implementation of systems, especially in developing countries. The study concluded that the rupture between the rigid model of the systems development process often fails to match the flexible sociopolitical reality of the organizational structure where it is applied. This conclusion leads to questions about the need for technological adaptation to foreign systems and a development model centered on local realities. Even though there may context similarities, that is, the use of a foreign system in a developing country, the model presented by the author addresses the deployment processes in an administrative environment that has very different characteristics in relation to a civil community.

In the field of usability, Kwee-Meier et al. [42] evaluated usability aspects that affect communication between mobile devices in critical emergencies. The study lists some critical emergencies in which information technologies are crucial, such as fires, nuclear emergencies, and others. As a result, some key recommendations to consider in the process of developing this type of application have been defined, such as memory reservation, simplified interface, use of strictly necessary information, and effective and constant loading of information. These recommendations are applicable to the process of 
developing a system, which is not the case in this paper, but these concepts can be useful to evaluate some aspects of using an application.

Although these works do not exactly deal with the same theme, the technological factor inserted in social contexts is present in all of them. The purpose of this study is to unite the three themes presented-acceptance, adherence, and security-for a comprehensive analysis of various factors inherent to the relationship between society and technology.

\section{Usability, adhesion, and access theoretical discussion}

In this section, the differences and similarities of each model are discussed, in addition to establishing the theoretical relationship between them. For Nielsen [35], the perception of utility is part of a set of factors called practical acceptance. The social acceptability described by the author may be to some extent equivalent to the nature of the social system. In turn, usability appears as an element that makes up the perception of utility in a hierarchical chain, unlike other models that level it with other factors.

Rogers [26] starts from the concept of innovation diffusion, describing the role of communication in this process. The author classifies adopters into five categories according to their willingness to embrace a new technology and describes five groups of factors that determine the success of technological diffusion. In particular, the perceived attributes of innovation construct contains characteristics very close to the elements contained in the practical acceptance described by Nielsen [35], such as compatibility and complexity. For this reason, the five factors of the perceived aspects of innovation construct were considered in the analytical model proposed herein. Moreover, thinking about new technology adoption cycles is pertinent to this research, as new applications are created for similar purposes and the competition between them directly affects users' perceptions of use.

The Rogers social system nature factor [26] or Nielsen's social acceptance configure aspects of influence on individual perceptions and attitudes. Van Dijk [27] focuses on individual technology access capabilities. At this point, it is possible to see parallels between the socioeconomic reality of individuals and the different levels of proficiency in the use of technology, crossing them with the adopter's profiles described by Rogers.

Following the idea of intersection between theories previously presented, Van Dijk's model [27] presents motivational access at the first level, which can be influenced by various subjective and social factors. Social acceptance, compatibility, and reliability, presented by Nielsen [35], are aspects that form a structural context for the dissemination and acceptance of technology, which Rogers classified as observability [26]. Thus, when the early adopter categories experience innovation and have positive attitudes toward it, a flow of information takes place in a given social environment that leads new adopters to use innovation. The application in this study uses sensitive user data, making it critical for Reliability to be established for the adhesion process to begin.

For collaborative security apps, this first level is of fundamental importance, because when a person uses this type of application, a relationship between "perceived advantage" and "risks" is made subjectively. When this relationship is positive, it leads to a technology acceptance attitude, even if there are concerns about the security of one's data. Relative advantage and perceived benefit are directly linked to information privacy [43]. For mobile devices, the cost-benefit ratio is even more delicate, as mobile devices 
have the ability to collect sensitive data full time everywhere, unlike personal computers [44]. This is evident from the people adhesion to social networks and online shopping apps. In this sense, what is called the privacy paradox in sensitive information occurs. Another pertinent issue is the influence of culture on social acceptance. Behavioral, legal, device access, and cost characteristics are part of the technology acceptance process.

Levels of material access, cost, and compatibility can be understood as the fundamental barriers to physical access. Compatibility can be explained as the convergence of available technologies required for the app, as well as the availability and access to mobile Internet and a smartphone capable of running the application. However, for Rogers [26], compatibility appears mainly as a set of subjective aspects that provide the conditions that lead to acceptance, that is, existing values, needs, and experiences.

At Van Dijk's digital skill levels, it is understood that the potential adopter has some expectation or opinion about innovation. At this point, the adopter's attitude is expressed positively or negatively.

The perception of utility influences the perception of relative advantage that, in this case, considers the cost-benefit perception that the application offers. When the adopters fail to realize the app utility, exposing their data can be a proportionately high cost, convincing them not to use the feature. On the other hand, if the potential adopters' attitude is positive at this level, there will be contact with innovation and, at this point, Usability may play an important role in influencing the experimentation and perception of complexity of technology. The user experience should be positive enough to influence users to continue using the technology, and the complexity level should be proportional with the expected capabilities of the target users.

Throughout the process, environmental and socioeconomic factors differently influence the different adopter profiles at some point in the adoption process. For example, higher income and educated adopters should not encounter obstacles at the first levels of access. Conversely, cultural issues may influence the perception of relative advantage, be it due to ethical, privacy, or gender perceptions $[45,46]$. However, at the last level of access described by Van Dijk [27], usage comprises those adopters who make full use of the technology and who already qualify as effective adopters. In this case, all the obstacles of the adoption cycle have been overcome.

\section{Method}

\section{Usability questionnaire definition}

In this section, we present how the prior explained concepts can integrate the unique model proposed in this research after combining its elements (Table 1).

As a first step, a usability questionnaire was elected to provide investigative support over the users' perceptions during the application use. After this, the questions constructs were associated to Nielsen's [35] usability concepts. Combining some factors inherited from Van Dijk's [27] model, these questions could be divided into four access levels. Finally, considering the social communication and context aspects, Rogers' [26] theory comes to reinforce the acceptance aspects correlated with the questions. Table 2 presents more details. 
Table 1 Usability issues. Source: the authors

\begin{tabular}{|c|c|c|}
\hline Construct & $\mathbf{N}^{\circ}$ & Item \\
\hline \multirow[t]{4}{*}{ Efficient use } & 1 & It was simple to use this app. \\
\hline & 2 & It was easy to find the information I needed. \\
\hline & 3 & It was easy to type the messages and insert images into the app. \\
\hline & 4 & The information on the application screen is well organized. \\
\hline \multirow[t]{3}{*}{ Ease of learning } & 5 & It was easy to learn how to use the app. \\
\hline & 6 & The symbols and buttons are intuitive enough. \\
\hline & 7 & I understood how the app works the first time I used it. \\
\hline Ease of remembering & 8 & I can quickly remember how to use the app after a while. \\
\hline \multirow[t]{3}{*}{ Error handling } & 9 & Whenever I made a mistake using the app, I could undo it easily and quickly. \\
\hline & 10 & The app offered error messages that clearly told me how to fix the issues. \\
\hline & 11 & $\begin{array}{l}\text { The information (such as online help onscreen messages and other documentation) } \\
\text { offered by the app was clear. }\end{array}$ \\
\hline \multirow[t]{3}{*}{ Efficiency } & 12 & The app quickly loads the information on the screen. \\
\hline & 13 & The messages were sent quickly. \\
\hline & 14 & I was able to complete tasks quickly using the app. \\
\hline \multirow[t]{3}{*}{ Effectiveness } & 15 & The app information was effective in helping me complete the tasks. \\
\hline & 16 & The application has not stopped working or has ever closed. \\
\hline & 17 & I believe it could quickly improve community surveillance with the app. \\
\hline \multirow[t]{2}{*}{ Satisfaction } & 18 & The application interface is nice. \\
\hline & 19 & I enjoyed using the application interface. \\
\hline \multirow[t]{2}{*}{ Acceptance } & 20 & I am satisfied with the application and intend to continue using it. \\
\hline & 21 & I want to encourage others to use this app. \\
\hline
\end{tabular}

From the questionnaires identified in this research, an evaluation of their items was performed in order to formulate the questions to be used. During the evaluation, problems such as complexity, confusion, redundancy, and high number of questions were found.

The questionnaires selected were SUS-System Usability Scale-adopted by Brooke [47], MPUQ-Mobile Usability Questionnaire-proposed by Ryu [48], a questionnaire adopted by Hussain and Kutar [49], another one proposed by Hoehle and Vankatesh [50], and, finally, the PSSUQ-Post-Study System Usability Questionnaire-proposed by Lewis [40].

The analysis of PSSUQ reveals that simplicity and objectivity are important points for an evaluation that seeks the generalization of a concept. Despite not designed to

Table 2 Relationship of theoretical approaches to usability issues. Source: the authors

\begin{tabular}{lllll}
\hline & N1 & N2 & N3 & N4 \\
\hline Van Dijk [26] & $\begin{array}{l}\text { Motivational } \\
\text { Access }\end{array}$ & Material Access & Access Skill (Instrumental) & $\begin{array}{l}\text { Access Skill (Informational/ } \\
\text { Strategic) }\end{array}$ \\
Nielsen [33] & $\begin{array}{l}\text { Social Acceptance, } \\
\text { Reliability }\end{array}$ & Compatibility, Cost & Usability & Utility \\
Rogers [25] & Observability & Compatibility & $\begin{array}{l}\text { Complexity, } \\
\text { Experimentation }\end{array}$ & Relative Advantage \\
Issues & Q19 & Q12, Q13, Q14, Q16 & Q1-Q6, Q8, Q9, Q18 & $\begin{array}{l}\text { Q7, Q10, Q11, Q15, Q17, } \\
\text { Q20, Q21 }\end{array}$ \\
\hline
\end{tabular}


specifically evaluate mobile applications, as well as others listed herein, it focuses on determining the degree of usage satisfaction, involving some generic usability features of any system. For this reason, PSSUQ was elected as the most consistent with this research; however, some adaptations were necessary.

For the better use of the information collected, some questions were removed or modified, and others were added to the questionnaire. The term "system" has been replaced by "application." One of the questions has been changed to emphasize improving community surveillance rather than questioning improving productivity. Additionally, a verification of the agreement of the dimensions approached by the PSSUQ in relation to the Nielsen [35] and ISO 9241-11 [33] classifications was performed. Note that the aspect of ease of remembering is not related to any item (Fig. 5).

Thus, a question regarding ease of remembering was added to the questionnaire. In addition, another question has been added to investigate usage intention to measure application acceptance level. Ten other questions related to the app were added, namely efficient use (issue 3), ease of learning (issues 6 and 7), ease of remembering (issue 8), efficiency (issues 12 and 13), effectiveness (issues 16 and 17), and acceptance (issues 20 and 21).

Although usability analysis is generally used to identify problems throughout the life cycle of the system, its concepts are used in this context to obtain the aspects of using an application in the use stage. Based on the usability issues defined at this stage, it is necessary to combine the three theoretical approaches proposed herein, presented in Table 2. The resulting questionnaire is presented in Table 1. Four access levels named

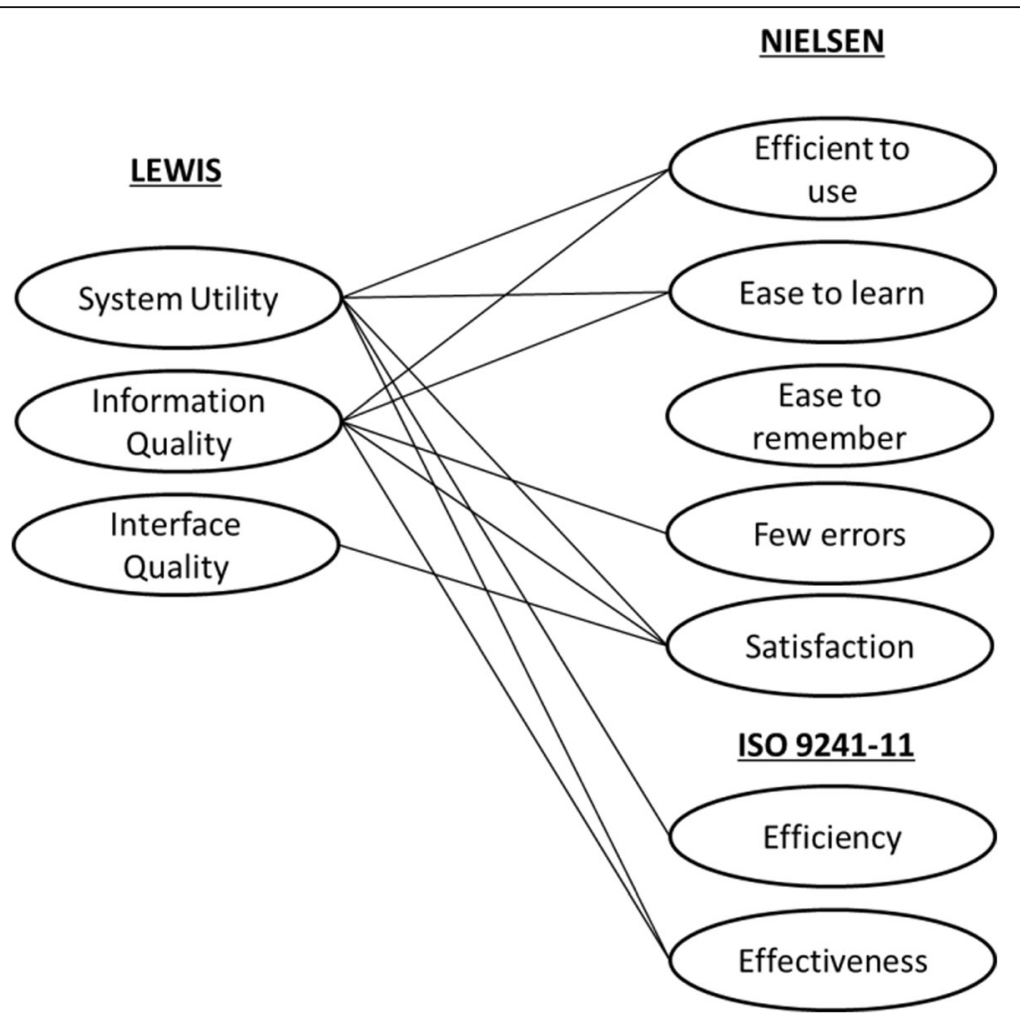

Fig. 5 Ratio of Lewis, Nielsen, and ISO 9241-11 dimensions. Source: the authors 
N1 to N4 are classified. Each level presents the correlated aspects of each theory and the convergence of the theories addressed with the corresponding questionnaire issues.

At the first level is issue 19, which verifies the appreciation of using the application interface, since this feature is understood as a relevant factor for motivational access. Regarding the "social acceptance" and "reliability" factors, information prior to the test application process should be considered. These issues are addressed in more detail in the section on results analysis.

The second level of access contains issues regarding application efficiency, as each device has its own processing power, just as each type of Internet connection interferes with the process. For "instrumental access," the "efficiency of use" and other questions that investigate the personal abilities to deal with the basic functions of the application were grouped. Finally, at the "informational access" level, there are issues that assess the quality of user information interpretation and the ability of the application to provide clear information.

Given the central objective of this research, the proposed model for the diffusion and adherence to the technology cycle is illustrated in Fig. 6.

According to the proposed model, the adhesion cycle begins when individuals have their first contact with a given innovation. The access levels are organized so that the user's individual ability to use technology becomes more complex. The number of users involved in the adoption cycle is expected to decrease as the process progresses.

It is understood that the first two levels, $\mathrm{N} 1$ and N2, are more influenced by external factors, either by social context or by physical and material conditions. For the next levels, the influence on the process of technology assimilation is largely exerted by subjective factors, such as the perception of complexity or relative advantage.

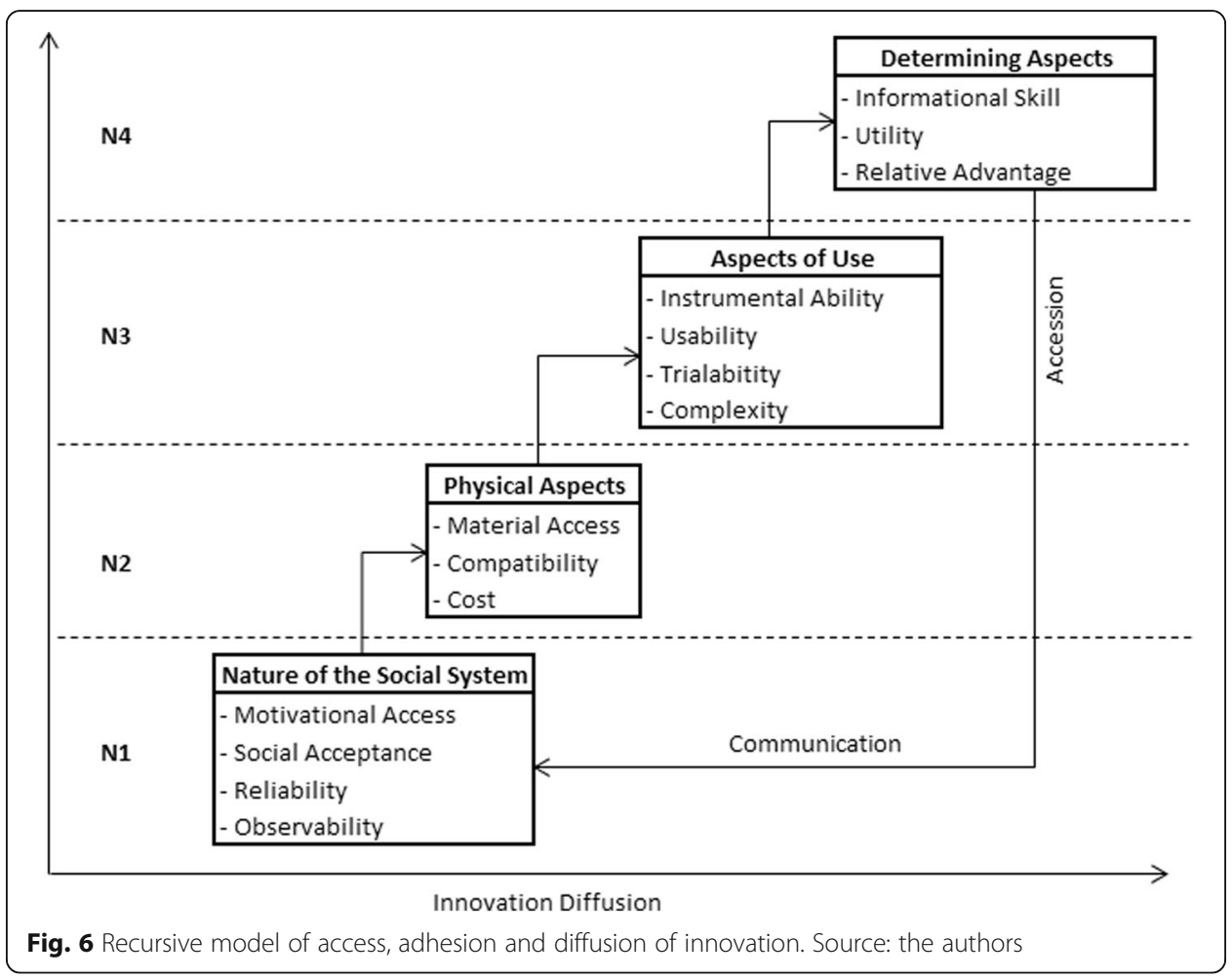


Communication is embedded in the process being exerted by the influencing agents involved in a social context. An individual becomes an influencing agent when he/she has knowledge and an opinion about the resource experienced. New users are inserted in the adhesion cycle by the positive perception of innovation, which characterizes the diffusion process. Thus, it is possible to reread the usability constructs by approaches that allow identifying the access levels and the attitude of users.

\section{Definition of procedures}

In this research, a case study was conducted from which we analyzed the different perceptions and acceptance levels of people living in the city of Itajubá, south of the State of Minas Gerais, in relation to the Life360 application. This municipality had an estimated population of 97,000 inhabitants in 2017, according to data from IBGE-Instituto Brasileiro de Geografia e Estatística [51]. The approach occurred in two ways: (i) through direct contact with the acquaintances of the researchers; and (ii) by inviting parents and students from two state schools in the city. The approaches were chosen seeing that this type of application requires a certain degree of confidence of the participants; therefore, the sampling model is configured as non-probabilistic convenience sampling. In this context, it is important to emphasize that this research followed the ethical precepts determined by Resolution $n^{\circ} 510$ [52], of April 7, 2016, and that, when volunteers were invited to participate in the research, they received an explanatory text about the objective of the research and the confidential character of the information collected. At the end of the explanation, those who agreed to participate in the research signed an informed consent form, as can be seen in Oliveira [46].

The study employed field research for its empirical process because this method aims to study a single group or community in terms of its social structure, highlighting the way its components interact [53]. For Günther [54], this method is interesting, especially from the point of view of qualitative research, enabling different approaches and techniques in the same study.

Data collection was performed by applying a questionnaire containing usability questions scored according to the five-point Likert scale, with answers ranging from 1 to 5, where 1 represents "totally disagree" and 5 represents "totally agree." This type of questionnaire is characterized as a structured interview, consisting of fixed questions, maintaining order and wording for all respondents [53].

The selection of the application studied was based on criteria such as language, available platforms, functionality, and group control. Particularly, the object of study is Life360, an application available for Android and iOS platforms whose purpose is to alert groups of people, called circles, about events and risk situations. The app also allows group communication with text messages and other media, as well as enabling a danger alert to be triggered for all the members of a group.

The usability test was the method chosen, because it is the evaluation of a product throughout the life cycle, including the use phase. In addition, it is suitable for the actual environment of use. The qualitative evaluation was performed empirically, which occurred through the application of a questionnaire to evaluate the usability and acceptance of the Life360 application. Additionally, a demographic questionnaire was applied to collect information about the profile of each participant. This questionnaire 
allowed us to identify the different levels of access to technology according to the access model presented by Van Dijk [27]. Participants were presented with a roadmap of activities to guide them in the process of using the application.

All content and explanatory material for the research were presented to participants through a web page available at: https://pesquisa-life360-unifei.firebaseapp.com. On the home page, there was a brief description of the survey and an explanatory video designed to attract the attention of younger applicants, as they are generally unwilling to read all the content presented. In a superior menu, as well as links distributed by the page contents, we presented the Life360 application, the informed consent form, the research execution script, and, finally, the questionnaire link. The questionnaire was made available with the help of the Google Forms tool, which allows to quickly gather all the answers obtained.

Study participants were asked to use the Life360 app for at least 3 weeks with family members. Guidance was for participants to respond to the questionnaire only after performing all the procedures presented at the end of the suggested period of use.

\section{Execution}

The execution of the study had the direct and indirect approach of the participants. Direct approaches took place through personal contact, telephone (26 people), email (four people), and text messaging in the Whatsapp app of people from the researcher's family and friendship circle, totaling 10 contacts. Indirect contacts occurred in Whatsapp groups and by an invitation letter distributed in two schools of the municipality, totaling 130 students approached in the sixth and seventh grades of elementary school.

The Whatsapp groups addressed were a neighborhood group of 53 participants; a group of students from ENEM (Exame Nacional do Ensino Médio) preparatory course with 106 students; a group of teachers of the same course with 12 members; and a group of 14 graduate alumni in Information Systems. Overall, 334 contacts were made, of which 22 answered the questionnaire.

The materials used were the participant user's smartphone, web page, and a video to disseminate the content and explain how the research was conducted, as well as the participant's own Internet.

In addition to the ethics term presented to the guests through the disclosure site, the free and informed consent for the participation of minors in the research is understood as the parents participating in the study with their children, thus having prior knowledge of objectives and risks inherent to the execution of the research.

\section{Discussion of results}

Table 3 presents the profiles of the survey participants. Female is identified by the letter $\mathrm{F}$ and male by the letter M; ages are distributed by ranges as described in the demographic questionnaire as well as household incomes with minimum wage ranges; education is synthesized with the abbreviations POS for complete postgraduate, GRAD for complete higher education, HS for complete high school, and PRIM for complete elementary school. The areas of professional practice are represented by abbreviations, TECH referring to technology, EDUC to education, STUD to student, ADM to administration, SELF for self-employed professionals and entrepreneurs, WORK for workers, 
Table 3 Demographic questionnaire results. Source: the authors

\begin{tabular}{|c|c|c|c|c|c|c|c|c|}
\hline & Gender & Age & Income & Education & Profession & Operational system & Device & Use \\
\hline$\overline{P 1}$ & $M$ & $31-40$ & $03-05$ & POS & EDUC & ANDR. & GALAXY S4 & 2 \\
\hline P2 & $\mathrm{F}$ & $31-40$ & 02-03 & $\mathrm{HS}$ & HOUS & ANDR. & ASUS & 2 \\
\hline P3 & M & $26-30$ & 03-05 & GRAD & TECH & ANDR. & AUSUS ZENFONE GO & 2 \\
\hline P4 & $\mathrm{F}$ & $26-30$ & 03-05 & GRAD & ADM & ANDR. & Moto $\mathrm{E}$ & 5 \\
\hline P5 & $\mathrm{F}$ & $31-40$ & $01-02$ & GRAD & SELL & ANDR. & SAMSUNG J5 & 2 \\
\hline P6 & M & $41-59$ & 03-05 & $\mathrm{HS}$ & SELF & ANDR. & SAMSUNG J5 & 5 \\
\hline P7 & $\mathrm{F}$ & $26-30$ & $05-10$ & GRAD & STUD & ANDR. & ASUS SELFIE & 5 \\
\hline P8 & M & $<18$ & $<01$ & $\mathrm{HS}$ & WORK & ANDR. & MOTO E 4 & 3 \\
\hline P9 & $\mathrm{F}$ & $31-40$ & $<01$ & $\mathrm{HS}$ & SELF & ANDR. & MOTO G 4 PLUS & 5 \\
\hline P10 & $\mathrm{F}$ & $31-40$ & $01-02$ & POS & EDUC & ANDR. & GALAXY GRAM DUOS & 3 \\
\hline P11 & M & $26-30$ & $01-02$ & GRAD & STUD & ANDR. & MOTO G 2 & 5 \\
\hline P12 & $\mathrm{F}$ & $18-25$ & 02-03 & $\mathrm{HS}$ & EDUC & ANDR. & SAMSUNG J5 & 2 \\
\hline P13 & $\mathrm{F}$ & $18-25$ & $01-02$ & PRIM & STUD & ANDR. & MOTO G $5 S$ & 3 \\
\hline P14 & $\mathrm{F}$ & $31-40$ & $05-10$ & POS & TECH & ANDR. & GALAXY S6 & 5 \\
\hline P15 & $\mathrm{F}$ & $26-30$ & 03-05 & POS & TECH & ANDR. & MOTO G4 & 5 \\
\hline P16 & M & $26-30$ & 03-05 & GRAD & TECH & ANDR. & ZENFONE 6 & 5 \\
\hline P17 & M & $26-30$ & 03-05 & POS & TECH & ANDR. & MOTO G P. & 5 \\
\hline P18 & $\mathrm{F}$ & $26-20$ & 03-05 & POS & EDUC & ANDR. & MOTO G5 P. & 5 \\
\hline P19 & $\mathrm{F}$ & $31-40$ & $01-02$ & $\mathrm{HS}$ & STUD & ANDR. & GALAXY DUOS & 3 \\
\hline P20 & $\mathrm{F}$ & $31-40$ & $02-03$ & $\mathrm{HS}$ & ADM & ANDR. & MOTO GT & 2 \\
\hline P21 & M & $<18$ & $01-02$ & PRIM & STUD & ANDR. & GRAN PRIME & 2 \\
\hline P22 & $\mathrm{F}$ & $41-59$ & $02-03$ & PRIM & WORK & ANDR. & GALAXY DUOS & 2 \\
\hline
\end{tabular}

HOUS for housewife, and SELL for seller. The operating system of all participants' devices was Android. Finally, the type of use is numbered between one and five, according to the order of the demographic questionnaire options, which also represents a degree of use (Table 4).

Note that more than $60 \%$ of the participants are female (Table 5). Possibly, this feature plays the role of mothers who are most interested in accompanying their children, while men may be more interested in tracking the location of their wives. This could be perceived in some participants' speech when asked about the research questions, as other observations described in the analysis. Another point observed is the type of smartphone usage reported by users, with almost half of the responses for level five usage (45.45\%). Is is possible to analyze these participants in a distinct group (group A) from the others, who declare to be between levels two and three, considered the second group, with $54.54 \%$ of the answers (group B). The analysis of these two user groups,

Table 4 Type of use. Source: the authors

\begin{tabular}{ll}
\hline Use & Goal \\
\hline 1 & Only for calls and text messages \\
2 & For calls, sending messages and some applications such as Whatsapp, Facebook and Instagram \\
3 & To play and for some applications such as Whatsapp, Facebook, and Instagram \\
4 & For everything, but there was some difficulty in setting up and in installing applications \\
5 & For everything, with good ability to configure and to install applications \\
\hline
\end{tabular}


Table 5 Demographic questionnaire category frequency. Source: the authors

\begin{tabular}{|c|c|c|c|c|c|}
\hline \multicolumn{2}{|c|}{ Gender } & \multicolumn{2}{|l|}{ Age } & \multicolumn{2}{|c|}{ Income } \\
\hline$F$ & $63.64 \%$ & $41-59$ & $9.09 \%$ & $<01$ & $9.09 \%$ \\
\hline \multirow[t]{4}{*}{$M$} & $36.36 \%$ & $31-40$ & $36.36 \%$ & $01-02$ & $27.27 \%$ \\
\hline & & $26-30$ & $36.36 \%$ & $02-03$ & $18.18 \%$ \\
\hline & & $18-25$ & $9.09 \%$ & 03-05 & $36.36 \%$ \\
\hline & & $<18$ & $9.09 \%$ & $05-10$ & $9.09 \%$ \\
\hline \multicolumn{2}{|c|}{ Education } & \multicolumn{2}{|c|}{ Profession } & \multicolumn{2}{|l|}{ Use } \\
\hline POS & $27.27 \%$ & $\mathrm{TECH}$ & $22.73 \%$ & 1 & $0.00 \%$ \\
\hline GRAD & $27.27 \%$ & EDUC & $18.18 \%$ & 2 & $36.36 \%$ \\
\hline $\mathrm{HS}$ & $31.82 \%$ & ADM & $9.09 \%$ & 3 & $18.18 \%$ \\
\hline \multirow[t]{5}{*}{ PRIM } & $13.64 \%$ & SELF & $9.09 \%$ & 4 & $0.00 \%$ \\
\hline & & WORK & $9.09 \%$ & 5 & $45.45 \%$ \\
\hline & & STUD & $22.73 \%$ & & \\
\hline & & HOUS & $4.55 \%$ & & \\
\hline & & SELL & $4.55 \%$ & & \\
\hline
\end{tabular}

here named $\mathrm{A}$ and $\mathrm{B}$, allows us to investigate their propensity to have a certain attitude toward the application. Theoretically, group A participants are expected to have better usage skills and tend to belong to the early adopter categories, making their acceptance tend to be more positive than the others.

That said, the analysis of the answers collected by the use questionnaire follows. For better guidance and understanding, the results are discussed following the order of access levels, classified according to Table 2. An acronym was adopted for each type of response, where TD means "totally disagree," PD means "partially disagree," $\mathrm{N}$ for "neutral" responses, PA for "partially agree" and,finally TA for "totally agree."

\section{The first level of access (N1)}

The first level (N1), which represents the intersection between the factors "Motivational Access," "Social Acceptance and Reliability," and "Observability," is associated with the questions of "subjective norm" or "social nature of the system" from the cultural and socioeconomic aspects of the municipality of application of the research. According to Nielsen's model, "social acceptance" is paralell to "practical acceptance"; however, people's attitude tends to be positive toward the application when there is the influence of the social environment that induces them to have a good perception of technology, which in turn leads them to risk experimenting with the artifact. For this reason, the observations made at this level are strongly focused on the non-respondent candidates who expressed some reason for not participating in the survey. Nevertheless, it is understood that question 19 ("I enjoyed using the application interface") may reflect the motivation of the user, who has reached a certain level of confidence to try Life360. The answers to this question are presented in Fig. 7.

Regarding usability, it is understood that satisfaction can positively influence the first impressions of use of the application. In this case, more than $60 \%$ of the participants totally agree to enjoy using the app. Of the TA responses in relation to the total answers (22), $50 \%$ are female (78\% of women versus $37 \%$ of men with this answer), $50 \%$ 


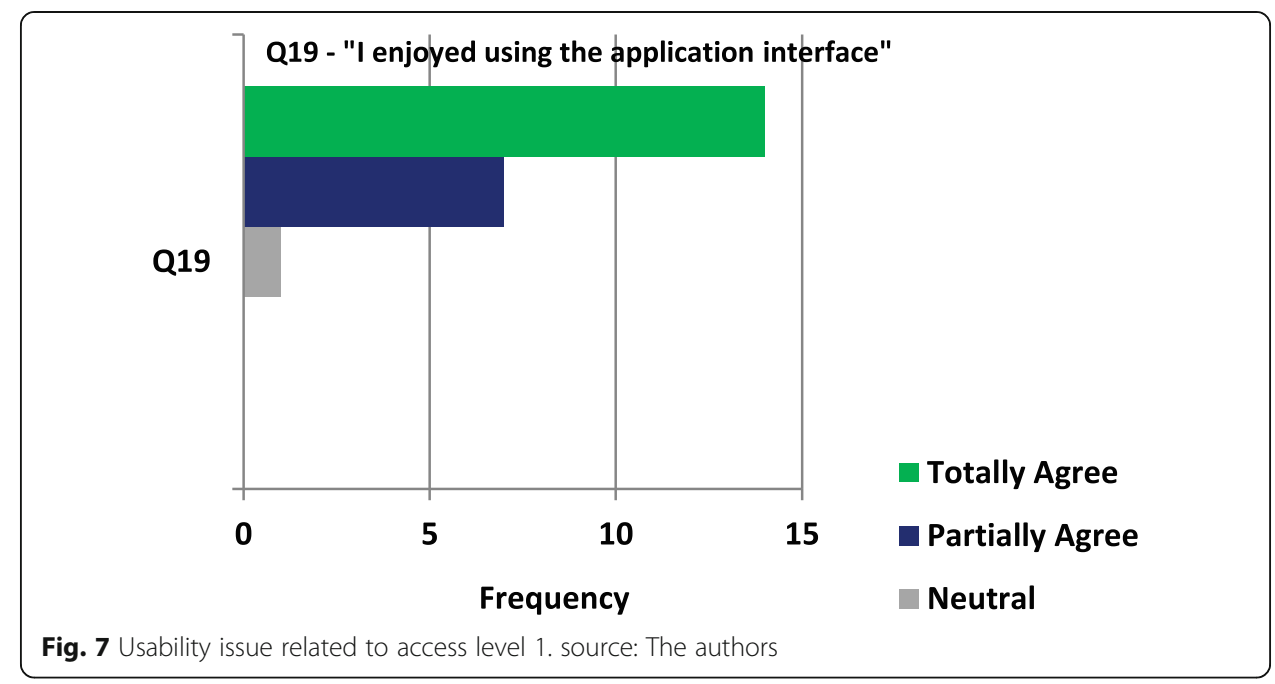

are between 26 and 30 years old, 27\% have incomes between one and three minimum wages, and $\sim 18 \%$ have incomes between three and five minimum wages. The fact that women are more attracted to the application interface than men may be related to the familiar theme presented in the images or to using more cheerful colors. Regarding the type of use, group A has $27.27 \%$ of the TA responses against group B which has $36.36 \%$ for the same response. Contrary to expectations, group B had greater appreciation for the application interface than group A. One possible explanation would be that users with less contact with applications feel more enthusiastic about novelty than those who already have past experience with other applications, which may also interfere with the expectation that the new application behaves similarly to others, respecting a usability standard. Perhaps because it is an application with a different purpose than the usual applications (Instagram, Whatsapp, and Facebook), the way to use it deviates from the expected standards.

When considering non-respondents to the survey, it is possible to assume that in order to motivate the use of the application, the individual must have prior knowledge about the innovation, so that an opinion can be formulated regarding the potential benefits offered. Since it is a relatively recent resource and has few users in the region studied, there is no influential group of innovators that can communicate the advantages of innovation in the social environment, making it difficult to disseminate the technology. Another important aspect that should be emphasized is that the research was entirely carried out with the voluntary participation of the candidates, that is, there was no imposition that forced their participation. This may explain the adherence of only $6.58 \%$ (22 people) of the survey guests.

During the direct telephone contacts with 26 parents of students from the two schools who received the invitation letter, nine explicity stated that they did not want to participate in the survey because they did not feel secure in providing personal information to the application. This phenomenon reveals that "reliability" is a central element in the motivation of individuals, as it is an unknown resource presented by an unknown person. In this case, doubts about the true purpose of the application makes the experimentation process difficult. 
Of the candidates contacted in person or by phone, six said they did not have enough memory space on their smartphones to install Life360. Two other candidates said they did not have a smartphone that could support installing the app. Another candidate reported that he only uses the Internet via his smartphone in places with a connection provided by the free city government and that he rarely buys the mobile operator's Internet data package. Because they do not have the minimum resources necessary to participate in the research, $2.69 \%$ of the candidates are not able to reach the level of material access, which falls under the second level of this study.

The second level of access (N2)

The components of the second interaction level (N2) are "material access," "compatibility," and "cost." As for compatibility, efficiency and effectiveness issues make sense in this dimension, as not all devices have equal processing capabilities. Compatibility can also be understood by the ability of hardware and software to interact seamlessly, which converges with the cost of each device. Therefore, issues related to this dimension are part of the efficieny and effectiveness constructs presented in Fig. 8.

When asked if the application loads the information quickly, or if the application has sttoped working at some point, the answers indicate that in some cases the operation was not fully satisfactory, as in question 12 ("The app quickly loads the information on the screen"), $50 \%$ of the answers were PA and $18.18 \%$ of the answers were N. Of the participants who answered PA, 63\% belonged to group $\mathrm{B}$ and $80 \%$ of $\mathrm{N}$ responses were from participants in group A. Among the respondents who answered TA, the distribution between groups is more homogeneous, with $57 \%$ of the responses belonging to group B. Probably, group A participants are most easily frustrated when the application is slow or crashes.

No cost relationships of the devices with their performance were observed, which leads to the hyphotesis that the problems occurred during use are linked to the quality

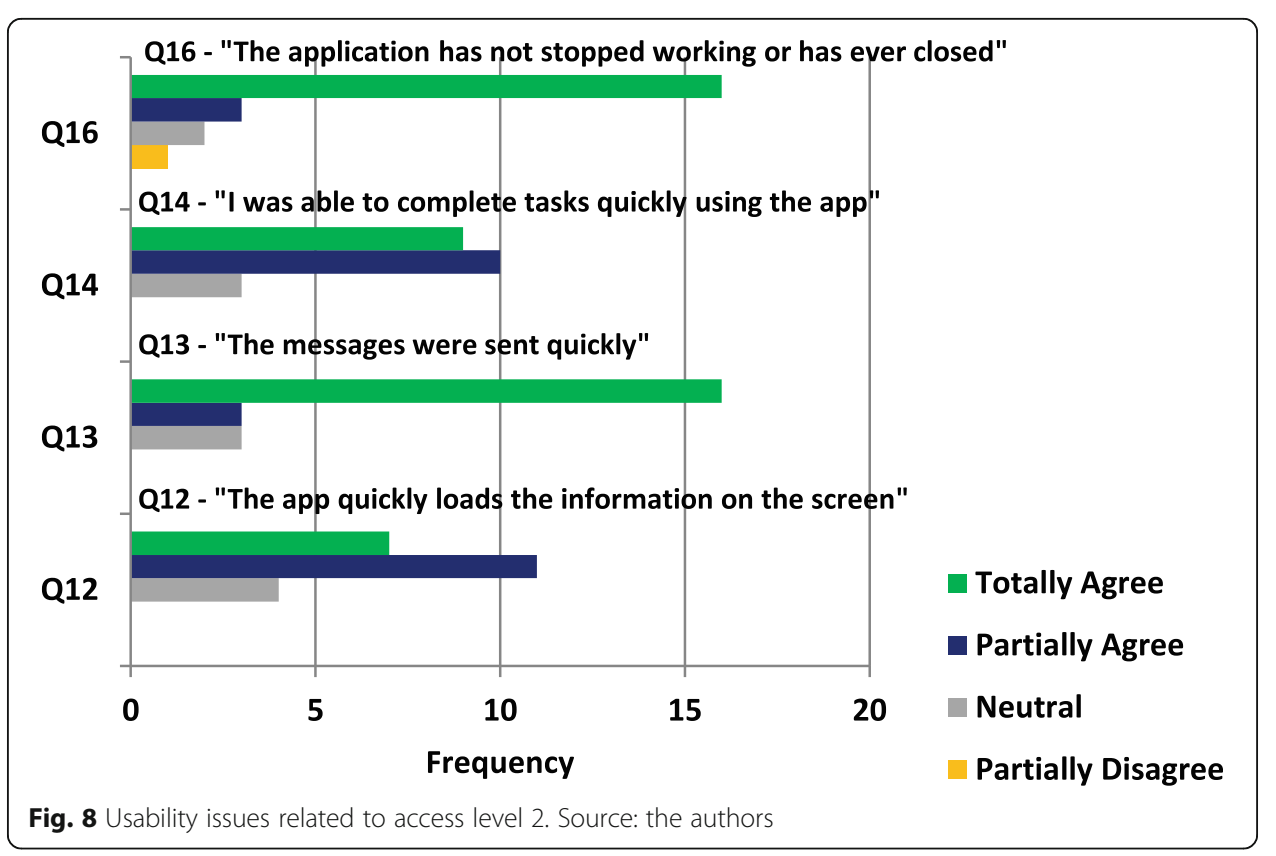


of the available Internet. In addition, regarding application failures, women had more negative responses than men, which may suggest different usage habits that may lead to system crashes. However, even women with the highest occurrence of failures were the ones who most appreciated the interface and the use of the system, which suggests greater tolerance for possible errors.

Respondents in group A generally had less positive responses than participants in group B. Interestingly, $18.18 \%$ of the participants in group B who answered TA are in the 31-40 age group. Everyone in this group with this answer has an income between one and three minimum wages. Maybe, for group A, realiability is more difficult to achieve, as they have a clearer perception of risks, which makes them think longer before taking action.

Question 16 returns the device ability to process the application, and access can be considered full or partial by considering that not all smartphones have the processing and storage power needed to run Life360, or that the Internet available is not sufficient to effectively exchange information. Thus, about $27.27 \%$ of the respondents did not have a full user experience, indicating application compatibility issues with features available to users. It was also identified that $83.33 \%$ of these respondents were female. Women may have particular usage habits, which may cause the device to occupy memory, causing Life360 to crash, or women may interact differently with the application interface, which could trigger some kind of runtime error in the system. Interestingly, although women have experienced some form of application malfunction, they are still the ones who most enjoyed interacting with the application interface, which may mean women's higher level of tolerance for system errors.

\section{The third level of access (N3)}

Regarding the third level of access defined in this research by the conjunction of "acess skill (instrumental)," "usability," and "complexity and experimentation," we highlight the issues related to the application interface and the ease for users to interact with the system.

Instrumental access, as explained, is described as the users' ability to work with hardware and software. Therefore, the usability constructs that most closely match these features are "Efficient Use," "Ease of Learning," "Ease of Remembering," "Error Handling," and "Satisfaction." In turn, "Complexity" and "Experimentation" are constructs directly influenced by the usability elements listed herein a positive correlation between these factors is expected. "Efficient Use" is understood as the ease of user interaction with the application interface, unlike the idea of efficiency in performing a task. The answers to this level are shown in Fig. 9.

"Efficient Use" (questions 1 to 4) generally presents a good level of agreement, with a $50 \%$ average of TA responses and $39.77 \%$ of average in PA answers.

For the first question ("It was simple to use this app"), there is a distribution of $54.54 \%$ of PA answers and $40.90 \%$ of TA answers. As for user groups, group A had $31.81 \%$ of PA responses and $13.63 \%$ of TA responses, compared to $27.27 \%$ of PA and TA responses for group B. Among the participants who answered TA, 22.72\% are between 31 and 40 years old and the same proportion has completed high school. Among those who answered PA, 27.27\% are between 26 and 31 years old and $22.72 \%$ have a 


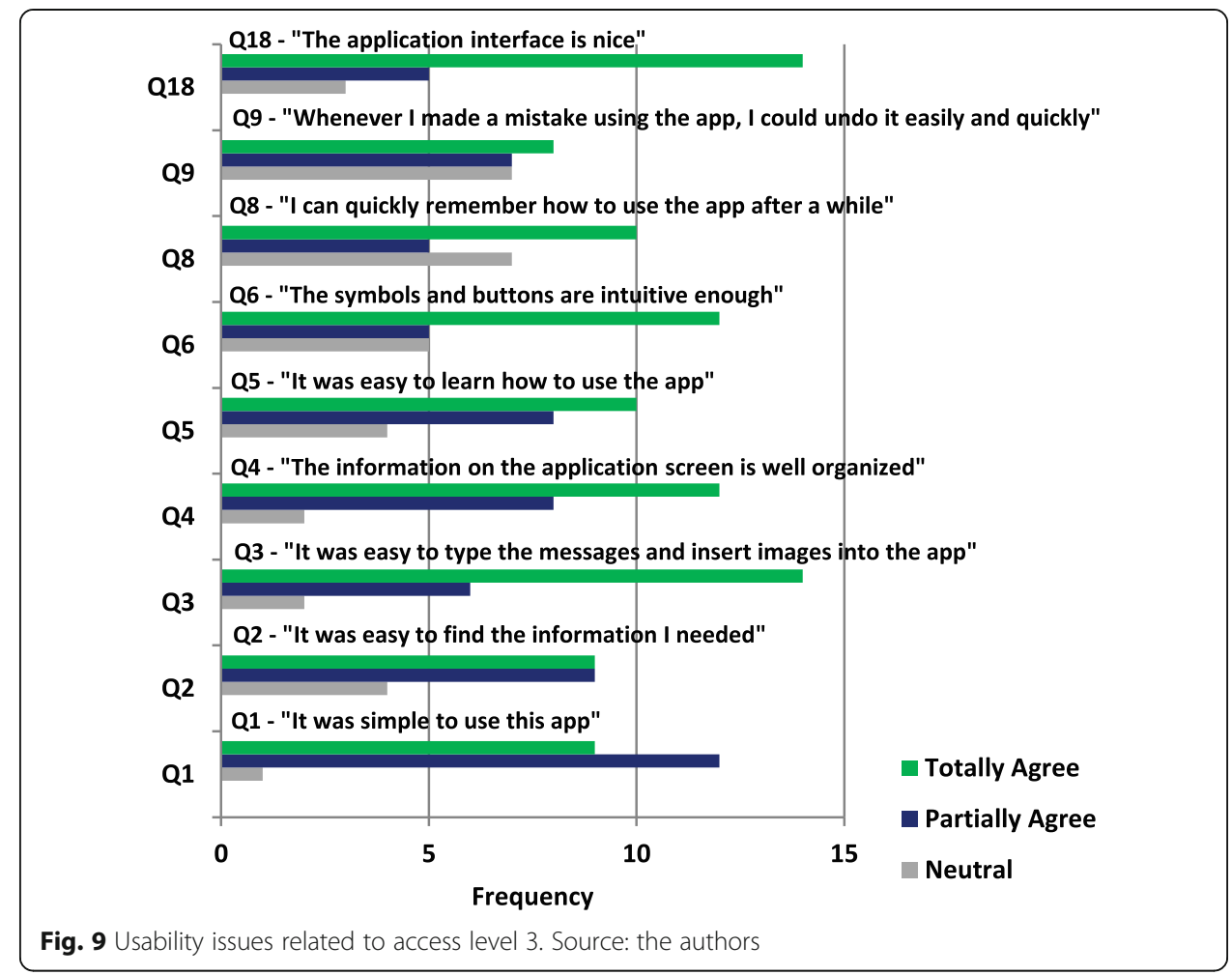

postgraduate degree, as well as the same proportion for income between three and five minimum wages. The answer to why older and less educated participants have more positive answers to ease of use than younger and more educated respondents can be found in the next issues.

The second question ("It was easy to find the information I needed") has $18.18 \%$ of $\mathrm{N}$ responses and $40.90 \%$ of PA and $40.90 \%$ of TA answers alike. For $\mathrm{N}$ responses, there is a uniform distribution between demographic classifications and between groups $\mathrm{A}$ and $\mathrm{B}$, but for PA and TA responses there is an inversion of distribution, and group A has $22.72 \%$ of PA responses against $18.18 \%$ of these answers for group B; for TA, responses are $13.73 \%$ of group A versus $27.27 \%$ of group B. This behavior may be one of the factors that would explain the answers to the first question, since group B participants stated that they were more likely to find the information they needed and this may explain the perception of ease of use.

In assessing the third question ("It was easy to type the messages and insert images into the app"), it is clear that the motor condition and the proximity to smartphone use are aspects that reflect not only the individual's capabilities, but also the ability of the interface to provide the necessary resource so that users, regardless of their capabilities, can perform well. Thus, $63.63 \%$ of the answers were TA, demonstrating good suitability of the application to users. However, it is interesting to note that the $\mathrm{N}$ answers were given by participants over 31 years old with completed high school.

In the fourth question ("The information on the application screen is well organized"), the answers would be expected to be as close as possible to the second question, since if the information is well organized it would soon be easy to find the necessary information. However, the answers to this question are more positive than to the second. 
Once again, the highest concentration of TA responses is from participants between 31 and 40 years old $(31.81 \%)$ who have completed high school $(27.27 \%)$. There is still a tendency for group B to have a better appreciation for this feature, with $45.45 \%$ of TA responses in this group versus just $9.09 \%$ of these responses for group A.

Possibly, older and less educated people are more flexible and easier to please with an interface, although they encounter some difficulties in handling the device. Regarding the fact that younger people declare more difficulty in finding information, the answer may be the impatience to read and interpret textual content, even with higher education, which would be aggravated by the intuitiveness and flow of use negatively perceived by these users.

As for "Ease of Learning" (questions 5 and 6), there is a slight increase in the $\mathrm{N}$ answers, a tendency that tends to increase this type of answer since the higher the level of access, the lower the level of adequacy for a current technology by thinking about the inovation adoption cycles proposed by Rogers [26].

In the fifth question ("It was easy to learn how to use the app"), answers $\mathrm{N}$ are well distributed in the categories of income, age, and education, but all belong to the participants in group B, which makes perfect sense, since they consider themselves to be poorly able to use smartphones. However, group B also had a higher concentration of TA responses (31.81\%), while group A had an equal proportion of PA responses. This is consistent with the characteristics raised in the first level of access, in which past experiences with other applications influence the perception and understanding of symbols in a negative way when there are differences in the standards adopted.

In the eighth question ("I can quickly remember how to use the app after a while"), $31.81 \%$ of the answers were $\mathrm{N}$ and $22.27 \%$ were PA. It appears that group B participants have better memory, with $31.81 \%$ of TA responses, than group A participants, with only $13.63 \%$ for this answer and $22.72 \%$ of responses $\mathrm{N}$. The same is true for users who are between 31 and 40 years old, with $22.72 \%$ of TA responses. It would be possible to relate this evidence to the different ability to concentrate for each age group. Possibly, younger people have lower ability to focus on one activity for a long time. Hence, process memorization is less efficient than for older people, who may be more patient and focused. However, the application proposal may arouse less interest in young audiences, which in turn would reduce the motivation to understand how the system works.

The ninth question ("Whenever I made a mistake using the app, I could undo it easily and quickly") is framed in the usability construct "Error Handling," though, is an issue that involves the flow of utilization, unlike questions 10 and 11 dealing with information. This issue can also be affected by the ease of finding the required information or interpreting symbols and buttons. Thus, an almost uniform distribution is observed between the N, PA, and TA responses. As noted earlier, the level of agreement tends to decrease as the level of access and complexity of application-user interactions increase. The even distribution of responses among demographic classifications and between groups A and B reveals that problems of fluidity in navigating functions are in the application itself, regardless of who uses it.

Finally, in question 18 ("The application interface is nice"), the answers were very favorable regarding "usage satisfaction," obtaining $63.63 \%$ of TA answers. Following the trend of previous questions pertaining to this level, the highest concentration of TA 
responses was $31.81 \%$ of participants aged $31-40$ years old. Satisfaction is understood as reflecting the sum of the results from the questions of "ease of use," "compatibility," and "complexity" previously evaluated. Thus, there is evidence that there is a correlation between the responses of each construct with the demographic characteristics of the participants.

In general, the level of "Instrumental Use" is well acepted because it presents a pleasant and quick understanding interface, revealing greater acceptance by older users, less educated, and belonging to group B. Nonetheless, participants that have the necessary motivational and physical conditions to use the application are expected to be able to "mechanically" use this type of feature, since the level of information required for its use is not very advanced, unlike the fourth level of access.

The fourth level of access (N4)

This level comprises the sense of "utility" and "relative advantage," determinants that reveal the influencing perceptions of attitude, and indicate more elements of the "social nature of the system"/"subjective norm"/"social acceptance" than previous access levels, therefore grouping the issues that address application acceptance and effectiveness. From the individual point of view, the "informational and strategic skill" involves the questions regarding the interpretation of information. All the questions pertaining to this level are shown in Fig. 10.

Observing the responses of this level, the higher frequency of disagreement compared to the previous levels is observed, as expected and explained above. It can be said that the understanding of how the application works is due to the good level of agreement

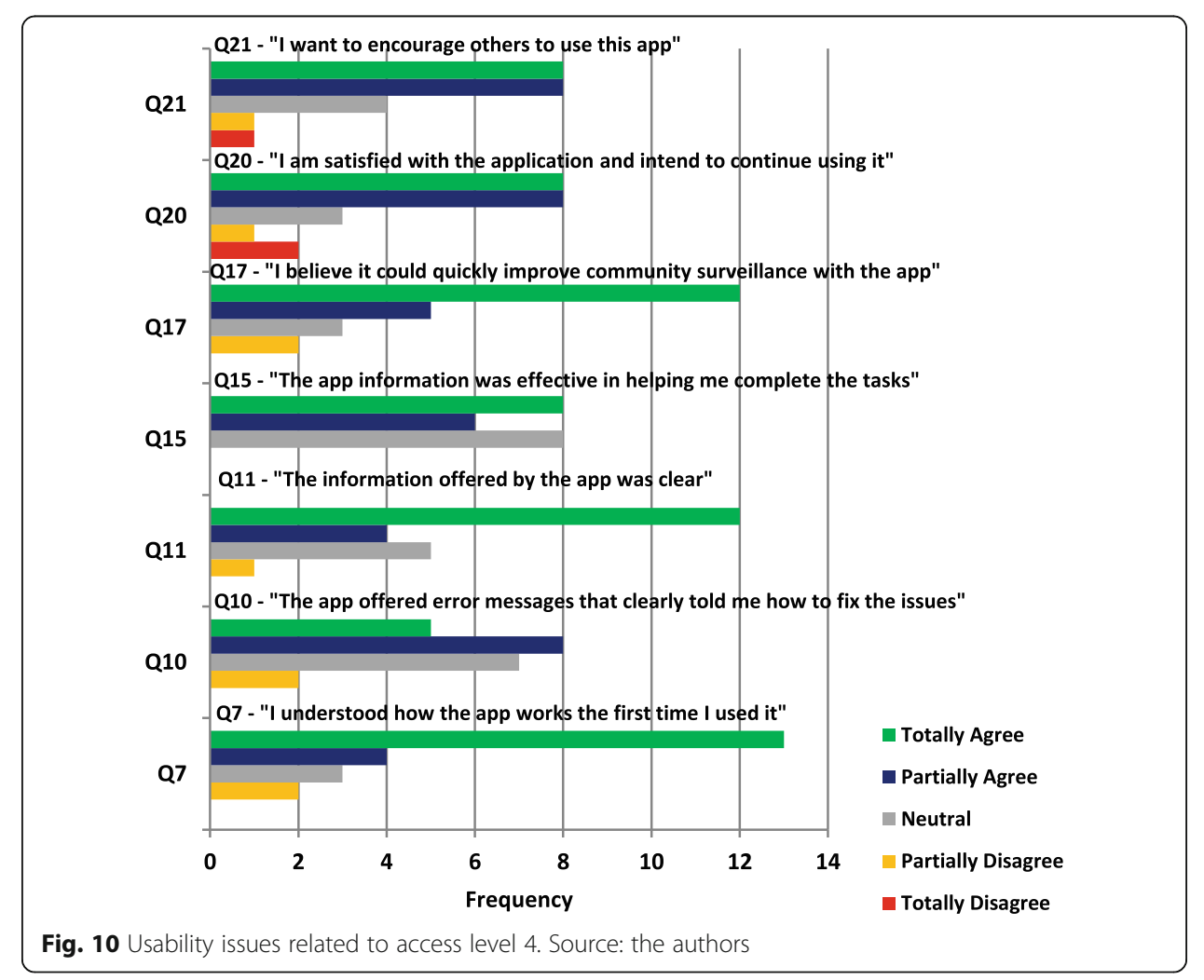


for usage issues, especially at the third level. However, understanding the operation of a technology may not necessarily mean that its purposes have been understood or that this factor is determinant for constructing the perception of "Relative Advantage."

For the seventh question ("I understood how the app works the first time I used it"), there are $9.09 \%$ of PD, all from group B participants. Among the other answers, there is an almost homogeneous distribution between groups and demographic classifications. With $59.09 \%$ of responses TA and $18.18 \%$ of answers PA, it can be said that the application is easy to understand. However, the neutral and discordant responses may be the result of dealing with an application that presents a very different proposal from the usual, as exposed in the first level of access. It also reveals the difficulty in understanding the application by less skilled users.

In the tenth question ("The app offered error messages that clearly told me how to fix the issues"), which deals with the quality of the information offered by the app, the level of agreement is low, with only $22.73 \%$ of responses TA. As for user groups, group A had more $\mathrm{N}$ responses, $22.72 \%$ against $9.09 \%$ of group B, while group B had more PA responses, $31.81 \%$, against $4.54 \%$ of group A. Regarding demographic classifications, once again there is a good distribution between the factors of age, income, and education. It seems that the low level of agreement is a result of the application failure to provide the necessary messages for a good understanding of the failures. Conversely, the application may have worked so well that there was no error situation, which is consistent with the answers to question 16, resulting in the high number of answers $\mathrm{N}$.

Then comes question 11 ("The information (such as online help onscreen messages and other documentation) offered by the app was clear"), which assesses both the individual's ability to interpret the information and the ability of the application to provide it. Thus, there is a concentration of $54.54 \%$ of TA responses, all female respondents, distributed in $36.36 \%$ for group B and $18.18 \%$ for group A. Still regarding these answers, $27.27 \%$ are between 31 and 40 years old and $22.72 \%$ have completed high school. Perhaps because they became more familiar with the application interface, as question 19 shows, women assimilated information better than men.

Regarding the "Effectiveness" approached by usability, questions 15 ("The app information was effective in helping me complete the tasks") and 17 ("I believe it could quickly improve community surveillance with an app") are distinguished at this level of access.

Question 15 reflects the same behavior as questions 9 and 10, and perhaps this is why $36.36 \%$ of the answers were N, $27.27 \%$ of PA answers and $36.36 \%$ for TA. For the user groups, $27.27 \%$ of the $\mathrm{N}$ answers were from group A versus $9.09 \%$ of group B. Among the TA answers, $22.72 \%$ are from participants between 31 and 40 years old belonging to group B. The fourteenth question can also be explained by these data, since group A feels less efficient in completing the tasks, and the perception of lack of information can also be one of the causes.

Question 17 is directly associated with the perception of "Utility" and "Relative Advantage." Since the purpose of the application is to provide means of mitigating possible detours, whether by kidnapping or an unexpected event, there were $9.09 \%$ of answers PD, $13.63 \%$ of responses $\mathrm{N}, 22.72 \%$ of answers PA, and $54.54 \%$ for TA. The $\mathrm{PD}$ responses are all from group A, a characteristic that evidences the influence of perceived risk and confidence in the perception of utility, which is consistent with the 
suspicion raised in the fourteenth question. Similarly, TA responses are concentrated in group B, with $36.36 \%$ versus $18.18 \%$ of group A.

Finally, questions 20 ("I am satisfied with the application and intend to continue using it") and 21 ("I want to encourage others to use this app") compose the usability "Acceptance" construct that expresses the intended use, that is, the attitude of users arising from a set of perceptions of utility and relative advantage over the resource.

In question 20, the distribution of the answers were 9.09\% TD, 4.54\% PD, $13.63 \% \mathrm{~N}$, $36.36 \%$ PA, and $36.36 \%$ TA. All N and discordant responses belong to group A. For the TD answers, their respondents belong to group A, are female, with complete higher education and an income above three minimum wages and aged between 26 and 30 . TA answers have $27.27 \%$ female responses and $22.72 \%$ have completed high school and $27.27 \%$ have an income between one and three minimum wages. Here, there are two basic issues to raise. The first concerns why younger, higher-income, more educated women have greater rejection of Life360 than lower-income and less educated women, and secondly, even though women in group A have enjoyed using the app, seen in question 19, there is still rejection by them. These young women are likely to prioritize their studies and careers over having children and caring for a family. It is also likely that there is some family structure that provides the security necessary to avoid worrying about violence or being financially able to live in less unsafe areas. For these reasons, using a smartphone as a security tool is likely to seem unnecessary from these perspectives. It could be said that the people who most need technology as a means of promoting quality of life have the least access to them.

The last question evaluates the potential of disseminating this technology in this social environment. Thus, with more than $70 \%$ of concordant responses (36.36\% PA and TA equally), there is a majority of participants who can spread the idea of using Life360. For the discordant and neutral responses, the same tendency as the previous question follows, which is consistent with the ideas presented in the TAM model, that the perception of utility is paramount in the acceptance process, or with the Innovation Diffusion Theory, in that the perception of utility spreads according to the belief of the early users.

The usability components are verified to establish relationships between them according to the demographic profile of users, but it is still necessary to explain how the elements of an access level interfere with the next level. The performance of the instrumental level of use is expected to yield corresponding results at the informational level, since the perceived ease of use and understanding the information are related. Yet Venkatesh and Davis [22] indicate that the perception of utility has a greater influence on attitude than the elements of ease of use.

By applying Pearson's correlation between the questions, eight occurrences were found with correlation coefficient $r>0.6$ (Table 6). Due to the restricted sample number, this value is considered a strong correlation.

The first correlation is between questions 2 and $6(p=0.001)$, which indicates that the ease of understanding symbols and buttons directly influences the ease of finding information in the application. Still correlated to question 6, the fourth question suggests that the perception of information organization on the application screen is positive when there is intuitiveness of the symbols used $(p<0.001)$. These correlations present interactions corresponding to the instrumental level of use, but the result set of 
Table 6 Correlation between the issues. Source: the authors

\begin{tabular}{|c|c|c|c|c|c|c|c|c|c|c|c|c|c|c|c|c|c|c|c|c|c|}
\hline Question & Q1 & $\mathbf{Q}^{2}$ & Q3 & Q4 & Q5 & Q6 & Q7 & Q8 & Q9 & \begin{tabular}{|l|} 
Q10 \\
\end{tabular} & \begin{tabular}{|l|} 
Q11 \\
\end{tabular} & Q12 & Q13 & \begin{tabular}{|l|l|} 
Q14 \\
\end{tabular} & \begin{tabular}{|l|l|} 
Q15 \\
\end{tabular} & Q16 & \begin{tabular}{|l|l} 
Q17 \\
\end{tabular} & \begin{tabular}{|l|} 
Q18 \\
\end{tabular} & \begin{tabular}{|l|} 
Q19 \\
\end{tabular} & \begin{tabular}{|l|} 
Q20 \\
\end{tabular} & Q21 \\
\hline Q1 & 1.00 & & & & & & & & & & & & & & & & & & & & \\
\hline Q2 & 0.56 & 1.00 & & & & & & & & & & & & & & & & & & & \\
\hline $\begin{array}{l}Q^{3} \\
\end{array}$ & -0.17 & 0.21 & 1.00 & & & & & & & & & & & & & & & & & & \\
\hline $\begin{array}{l}\text { Q4 } \\
\end{array}$ & 0.41 & 0.45 & \begin{tabular}{|c|} 
\\
\end{tabular} & 1.00 & & & & & & & & & & & & & & & & & \\
\hline Q5 & 0.41 & 0.55 & \begin{tabular}{|c|}
-0.03 \\
\end{tabular} & 0.30 & 1.00 & & & & & & & & & & & & & & & & \\
\hline Q6 & 0.53 & 0.64 & \begin{tabular}{|c|}
-0.15 \\
\end{tabular} & 0.66 & 0.60 & 1.00 & & & & & & & & & & & & & & & \\
\hline \begin{tabular}{|l|} 
Q7 \\
\end{tabular} & 0.38 & 0.35 & \begin{tabular}{|l|l|}
-0.16 \\
\end{tabular} & 0.36 & 0.62 & 0.56 & 1.00 & & & & & & & & & & & & & & \\
\hline $\begin{array}{l}\text { Q8 } \\
\end{array}$ & 0.36 & 0.59 & 0.03 & 0.45 & 0.29 & 0.39 & 0.22 & 1.00 & & & & & & & & & & & & & \\
\hline $\mathbf{Q}^{9}$ & 0.26 & 0.51 & \begin{tabular}{|l|l|}
0.04 \\
\end{tabular} & 0.30 & 0.57 & 0.52 & 0.48 & 0.05 & 1.00 & & & & & & & & & & & & \\
\hline Q10 & 0.10 & 0.23 & \begin{tabular}{|l|}
-0.06 \\
\end{tabular} & 0.36 & 0.11 & 0.18 & 0.03 & 0.39 & 0.02 & 1.00 & & & & & & & & & & & \\
\hline Q11 & 0.18 & 0.19 & \begin{tabular}{|l|}
-0.05 \\
\end{tabular} & 0.49 & 0.36 & 0.49 & 0.36 & 0.02 & 0.57 & \begin{tabular}{|l|} 
\\
\end{tabular} & 1.00 & & & & & & & & & & \\
\hline Q12 & 0.45 & 0.39 & \begin{tabular}{|l|l|} 
& 0.04 \\
\end{tabular} & 0.36 & 0.45 & 0.24 & 0.27 & 0.65 & 0.07 & \begin{tabular}{|l|} 
\\
\end{tabular} & \begin{tabular}{|l|}
0.30 \\
\end{tabular} & \begin{tabular}{|l|}
1.00 \\
\end{tabular} & & & & & & & & & \\
\hline Q13 & 0.03 & 0.26 & \begin{tabular}{|l|}
0.28 \\
\end{tabular} & 0.49 & 0.21 & 0.22 & 0.22 & 0.53 & 0.26 & 0.32 & 0.40 & \begin{tabular}{|l|}
0.57 \\
\end{tabular} & 1.00 & & & & & & & & \\
\hline Q14 & 0.33 & 0.51 & \begin{tabular}{|l|l|}
-0.13 \\
\end{tabular} & 0.23 & 0.39 & 0.49 & 0.35 & 0.24 & 0.46 & -0.10 & \begin{tabular}{l|l}
0.25 \\
\end{tabular} & \begin{tabular}{|l|}
0.21 \\
\end{tabular} & 0.23 & 1.00 & & & & & & & \\
\hline Q15 & 0.28 & 0.36 & \begin{tabular}{|l|l|}
-0.16 \\
\end{tabular} & 0.41 & 0.21 & 0.33 & 0.21 & 0.31 & 0.32 & 0.18 & 0.39 & \begin{tabular}{|l|}
0.23 \\
\end{tabular} & 0.37 & 0.31 & 1.00 & & & & & & \\
\hline Q16 & -0.13 & 0.32 & 0.45 & 0.05 & 0.12 & 0.01 & -0.28 & 0.40 & \begin{tabular}{|c|}
-0.04 \\
\end{tabular} & \begin{tabular}{|c|} 
\\
\end{tabular} & \begin{tabular}{|l|}
-0.10 \\
\end{tabular} & \begin{tabular}{|l|}
0.26 \\
\end{tabular} & 0.45 & \begin{tabular}{|l|l|}
5 & -0.02 \\
\end{tabular} & 0.19 & 1.00 & & & & & \\
\hline Q17 & 0.18 & 0.12 & 0.16 & 0.19 & -0.02 & 0.02 & $\mid-0.20$ & 0.33 & \begin{tabular}{|c|}
-0.18 \\
\end{tabular} & 0.37 & \begin{tabular}{|l|}
0.09 \\
\end{tabular} & \begin{tabular}{|l|}
0.48 \\
\end{tabular} & 0.58 & \begin{tabular}{|l|l|}
8 & 0.24 \\
\end{tabular} & 0.11 & 0.23 & 1.00 & & & & \\
\hline Q18 & 0.11 & 0.13 & 0.00 & 0.48 & 0.34 & 0.27 & \begin{tabular}{|l|} 
\\
\end{tabular} & 0.04 & 0.27 & 0.21 & 0.76 & \begin{tabular}{|l|}
0.41 \\
\end{tabular} & 0.39 & \begin{tabular}{|l|l|}
9 & 0.00 \\
\end{tabular} & 0.44 & 0.08 & $\begin{array}{ll}0.03 \\
\end{array}$ & 1.00 & & & \\
\hline Q19 & 0.32 & 0.54 & 0.23 & 0.49 & 0.36 & 0.47 & \begin{tabular}{|l|} 
\\
\end{tabular} & 0.29 & 0.23 & \begin{tabular}{|l|} 
\\
\end{tabular} & 0.42 & \begin{tabular}{|l|}
0.59 \\
\end{tabular} & 0.36 & \begin{tabular}{|l|l|}
6 & 0.17 \\
\end{tabular} & 0.18 & 0.27 & 0.32 & 0.60 & 1.00 & & \\
\hline Q20 & 0.07 & 0.19 & 0.09 & 0.19 & 0.04 & 0.13 & -0.27 & 0.32 & \begin{tabular}{|c|}
-0.08 \\
\end{tabular} & 0.13 & 0.07 & 0.24 & 0.46 & \begin{tabular}{|l|l|}
6 & 0.26 \\
\end{tabular} & 0.18 & 0.38 & 0.81 & \begin{tabular}{|c|}
-0.03 \\
\end{tabular} & 0.18 & 1.00 & \\
\hline Q21 & -0.12 & 0.13 & 0.17 & 0.16 & -0.16 & -0.09 & -0.24 & 0.15 & 0.11 & \begin{tabular}{|c|} 
\\
\end{tabular} & 0.14 & \begin{tabular}{|l|}
0.19 \\
\end{tabular} & 0.57 & \begin{tabular}{|l|l|}
7 & 0.20 \\
\end{tabular} & 0.25 & 0.38 & 0.69 & 0.15 & 0.27 & \begin{tabular}{|l|} 
\\
\end{tabular} & 1.00 \\
\hline
\end{tabular}

these interactions can result in the ease of learning to use the application (Q5-instrumental), which is positive when understanding the application is easy (Q7-informational) ( $p=0.001)$, or that the clarity of information (Q11-informational) makes the experience of using the interface (Q18-instrumental) more enjoyable $(p<0.001)$, or vice versa.

As for the ease of remembering how the application works (Q8-instrumental), efficiency has a positive correlation in this regard when information is loaded quickly (Q12-physical) ( $p=0.001$ ). Maybe fluidity in use decreases the user's anxiety, which may cause greater immersion in the user experience.

However, the perception of effectiveness (Q17-informational) has the highest level of correlation with intention of use (Q20-informational) $(p<0,001)$ and intention to disseminate technology (Q21-informational) $(p<0.001)$. These numbers corroborate the ideas that the perception of utility is more relevant than the usability characteristics of the application.

To measure the reliability of the questionnaire, Cronbach's alpha was applied to obtain the internal consistency of the items. According to Pereira [55], this measurement varies between 0 and 1, which means 1 is the highest level of item consistency. Malhotra [56] states that the minimum acceptable value is 0.6 , whereas George and Mallery [57] provide a scale of values where 0.9 is excellent, 0.8 is good, 0.7 is acceptable, and 0.6 is questionable.

To calculate Cronbach's alpha, IBM SPSS Statistics was used. First, all the items in the questionnaire were applied and the result was 0.866 , which means a very good consistency, as shown in Table 7.

Although the high level of reliability means that the entire questionnaire has a good consistency, it is necessary to investigate the individual influence of the items in the global context. Therefore, Table 8 shows the results if each item is removed.

Table 7 Reliability of items. Source: the authors

\begin{tabular}{lll}
\hline Cronbach's alpha & Cronbach's alpha based on standardized items & N of items \\
\hline 0.866 & 0.877 & 21 \\
\hline
\end{tabular}


Table 8 Item-total statistics. Source: the authors

\begin{tabular}{llll}
\hline Question & Cronbach's alpha if the item is deleted & Question & Cronbach's alpha if the item is deleted \\
\hline Q1 & 0.862 & Q12 & 0.855 \\
Q2 & 0.854 & Q13 & 0.852 \\
Q3 & 0.871 & Q14 & 0.861 \\
Q4 & 0.855 & Q15 & 0.859 \\
Q5 & 0.858 & Q16 & 0.866 \\
Q6 & 0.855 & Q17 & 0.860 \\
Q7 & 0.866 & Q18 & 0.860 \\
Q8 & 0.856 & Q19 & 0.856 \\
Q9 & 0.861 & Q20 & 0.864 \\
Q10 & 0.865 & Q21 & 0.863 \\
Q11 & 0.859 & & \\
\hline
\end{tabular}

As can be seen in the previous table, even if an item is removed, the alpha value remains above 0.8 , which means that none of the questions is in disagreement with the questionnaire. In addition, the alpha value was applied to levels N2, N3, and N4 (Table 9). Level N1 was not applied because it has only one question. As shown in Table 9, only the N3 level is close to the 0.8 score; $\mathrm{N} 2$ and $\mathrm{N} 4$ are close to the 0.6 score.

Given the low values obtained in each construct, it is valid to evaluate what could be interfering with the results. Therefore, evaluating each construct individually allows weakness points to be identified in the instrument so that, in future researches, the necessary corrections are applied before using the model. For more details on each issue at their respective levels, the following tables show alpha values in case a question is removed.

Looking at Table 10, Q14 is verified to have changed the score from 0.606 to 0.680 , which could cause a sligh improvement. Question 14 ("I was able to complete tasks quickly using the app") refers to the perception of efficiency by users, which is an important aspect to be investigated, especially in this specific study that refers to a safety mobile application. As a suggestion for further research, this aspect can be analyzed by taking specific tasks instead of the global perception.

Table 11 shows that the removal of Q3 could improve the score from 0.797 to 0.834 . This question refers to the perception of typing messages and inserting images. Similar to $\mathrm{N} 2$, this question deals with an important aspect of using the application because the elderly population can be a large group of users.

For N4, Table 12 shows an improvement in the alpha score from 0.653 to 0.731 when Q7 is removed. In this case, Q7 refers to the user's understanding of the application in the first use. Looking for the definition of N3 (Access Ability-Instrumental) in Table 2, the

Table 9 Cronbach alpha in levels. Source: the authors

\begin{tabular}{llll}
\hline Level & N2 & N3 & N4 \\
\hline Cronbach's alpha & 0.606 & 0.797 & 0.653 \\
Average & 4.386 & 4.318 & 4.039 \\
Variance & 0.568 & 0.572 & 1.061 \\
N of Items & 4 & 9 & 7 \\
\hline
\end{tabular}


Table 10 Total-item statistics for N2. Source: the authors

\begin{tabular}{llll}
\hline Question & Cronbach's alpha if the item is deleted & Question & Cronbach's alpha if the item is deleted \\
\hline Q12 & 0.455 & Q14 & 0.680 \\
Q13 & 0.337 & Q16 & 0.604 \\
\hline
\end{tabular}

"Complexity" aspect of Rogers [25] could make more sense for this issue. Thus, the suggestion for further research is to move Q7 from N4 to N3.

Note that in every construct, there is always a question that significantly interferes. In order to achieve at least 0.7 reliability points, making the instrument viable for future applications, improvements are necessary to obtain the desired reliability before applying the instrument.

\section{Final considerations}

This research aimed to evaluate the influence of social dimensions on the process of acceptance and access to technology through a usability study for collaborative security applications. To this end, the main usability fundamentals were raised, as well as various study models on technological acceptance and access to technology. The main applications developed to promote collaborative security were raised, as well as usability studies focused on this category of applications. The compilation of all this information resulted in a questionnaire covering the most reputable usability constructs, adapted for evaluating a smartphone application and grouped in the order corresponding to the levels of access and adherence to technology.

The analytical restructuring of usability allowed identifying components pertaining to the nature of social structure and acceptance, user profiles, and Life360 level of suitability for participants. The importance of this rereading is the possibility of perceiving the distance between the conception of technology and the different social realities existing in a region. Thus, when the usability assessment is performed at four levels of access, there is a bottleneck of participants who are likely to use and spread Life360 as levels rise.

At the first level focusing on "Motivational Access," "Social Acceptance," "Reliability," and "Observability," aspects of the social structure that lead people to experience a new technology have been observed. In this context, the attitudes of the candidates regarding the research were considered, and several did not agree to participate given the nature of the information involved. Typically, academic papers perform their analyses based on the respondents to their questionnaires or participants in their experiments. However, when it comes to accepting an innovation, one must be aware of the subjective aspects of non-respondents, i.e., what reasons influenced these individuals' refusal

Table 11 Total-item statistics for N3. Source: the authors

\begin{tabular}{llll}
\hline Question & Cronbach's alpha if the item is deleted & Question & Cronbach's alpha if the item is deleted \\
\hline Q1 & 0.777 & Q6 & 0.741 \\
Q2 & 0.737 & Q8 & 0.788 \\
Q3 & 0.834 & Q9 & 0.775 \\
Q4 & 0.764 & Q18 & 0.799 \\
Q5 & 0.757 & & \\
\hline
\end{tabular}


Table 12 Total-item statistics for N4. Source: the authors

\begin{tabular}{llll}
\hline Question & Cronbach's alpha if the item is deleted & Question & Cronbach's alpha if the item is deleted \\
\hline Q7 & 0.731 & Q17 & 0.537 \\
Q10 & 0.641 & Q20 & 0.560 \\
Q11 & 0.631 & Q21 & 0.547 \\
Q15 & 0.617 & & \\
\hline
\end{tabular}

to participate. Thus, the role of trust in the adoption process was evidenced, as well as the influence of culture on the perception of reliability.

Another interesting feature to note is that Life360 is little known by the participants, which makes the aspect of observability poor, since there is no presence of influencers acting on the subjective norm. Therefore, this set of factors may explain the low number of volunteers supporting the research. Moreover, collaborative applications have their own characteristics, since by the theory of diffusion, it is not enough for the initial innovators to be perceived, but that this group is formed by members of the same medium, with sufficient engagement for the effects of innovation to be perceived by other social groups. The lack of influencers slows down the spread of collaborative applications, which demands greater insistence and punctual work. Influencers should positively affect members of their community and other groups with similar goals.

Regarding the questionnaire, it was considered a question that evaluates the appreciation of the application by users and it was found that the majority of females present more favorable answers than men. This behavior may not be coincidental, assuming Life360 is designed for mothers to keep track of their children's movement. This assumption indicates a good agreement of the system design with social reality, at least in this respect.

The attitudes of the research candidates who stated that they did not have the necessary resources to participate in the study were considered. This observation reveals that despite technological ubiquity, material access is still an important barrier against the adoption process, and clarifies the misperception or common sense that the entire population currently has a smartphone and access to the Internet.

The findings from this research lead us to believe that, although the initial factors of access have a positive evaluation, the social aspects are essential determinants for the intention of use to be positive, corroborating the theories presented. Additionally, the contribution of the proposed multitheoretical analytical model is evident, since it allows understanding influence factors on usability that would hardly be perceived through an analysis focused solely on usability. Although some models try to understand the psychological profile of users, their approach is limited to pointing out which features of the system are more or less desirable. In addition, the informational level has a great influence on the perceptions of use, either by the demographic characteristics of the participants or the features of the application. In turn, the set of influences at the informational level is decisive for forming the user's attitude, whether positive or negative.

Finally, it is understood that the limitations of this work are due to the sample size, given the need for a high level of trust between the participants and the researchers. In future works, there is the possibility to apply this approach to more densely populated regions and with different social realities from the municipality studied, so that it is 
feasible to perform statistical analyses on the results. Although the questionnaire consists of well-known constructs in the academic literature on usability, it is necessary to statistically reassess the validity of the analysis model used based on convergent theories. In addition, the social context is very complex and includes a large number of factors that can be considered key elements to influence the behavior of users related to the application. New questions related to other aspects could be included in the questionnaire, such as the physical environment in which the participants live, considering public lighting and sanitation, subjective perception of safety, or even the distance between work and home [58]. Moreover, social-political differences are also points that should be considered, for example, the criminality level of the studied region. In this case, the city where the study was conducted has a low level of criminality. It would thus be interesting to apply this research to different regions of Brazil to involve safety and cultural aspects. These new levels of complexity could enrich the analysis of the perception of users of the application.

\begin{abstract}
Abbreviations
ENEM: Exame Nacional do Ensino Médio (Senior High-School National Exam); HCl: Human-computer interaction; HCI4D: Human-computer interaction for development; IBGE: Instituto Brasileiro de Geografia e Estatística (Brazilian Institute of Geography and Statistics); ICTs: Information and communication technologies; MPUQ: Mobile Phone Usability Questionnaire; PSSUQ: Post Study System Usability Questionnaire; SUS: System Usability Scale; UCD: Usercentered design; UX: User experience
\end{abstract}

\title{
Acknowledgements
}

The authors would like to thank all the participants who voluntarily acted in this research.

\section{Authors' contributions}

MO: This paper aims to present the study generated for the author's master thesis. APM: She advised MO in his master degree. Her contribution is mainly based on the academic advisory and as a partner for making decisions during the master degree. RDS: He was the co-advisor of $\mathrm{MO}$ in his master thesis. His contribution is mainly based on academic advisory and as a partner for making decisions during the master studies. All the authors have read and approved the final manuscript.

Funding

The authors declare that they have no funding.

Availability of data and materials

The authors declare that all data and materials are available at Oliveira [45].

Competing interests

The authors declare that they have no competing interests.

\section{Author details}

${ }^{1}$ Institute of Production and Management Engineering, Federal University of Itajubá, Itajubá, MG, Brazil. ${ }^{2}$ Institute of Mathematics and Computing, Federal University of Itajubá, Itajubá, MG, Brazil.

Received: 23 January 2020 Accepted: 12 February 2021

Published online: 23 February 2021

\section{References}

1. Castells M (1999) A sociedade em rede. v. 1, 8. São Paulo: Paz e Terra

2. McLoughlin C, Lee M (2007) Social software and participatory learning: pedagogical choices with technology affordances in the Web 2.0 era. In: Proceedings ascilite Singapore, pp 664-675

3. Rand DG, Arbesman S, Christakis NA (2011) Dynamic social networks promote cooperation in experiments with humans. Proceedings of the National Academy of Sciences 108(48):19193-19198

4. Elger TTC (2010) Redes tecnossociais e democratização das políticas públicas. Sociologias 23:208-236

5. Facebook (2018) Company Info. http://newsroom.fb.com/company-info/. Accessed:

6. Statista (2018) Device usage of Facebook users worldwide as of January 2018. https://www.statista.com/statistics/3 77808/distribution-of-facebook-users-by-device/. Accessed: .

7. Statista (2018) Number of mobile messages sent through WhatsApp as of 4th quarter 2017 (in billions). http://www.sta tista.com/statistics/258743/daily-mobile-message-volume-of-whatsapp-messenger/. Accessed: .

8. Wellman B (2001) Computer networks as social networks. Science 293(5537):2031-2034

9. Ho M, Smyth T, Kam M, Dearden A (2009) Human-computer interaction for development: The past, present, and future. Inform Technol Int Development 5(4):1-18 
10. Toyama K (2010) Human-computer interaction and global development. Foundations and Trends in Human-Computer Interaction 4(1):1-79

11. Tomlinson B, Silberman M, Patterson D, Pan Y, Blevis E (2012) Collapse informatics: augmenting the sustainability \& ICT4D discourse in HCl. In: Proceedings of the SIGCHI Conference on Human Factors in Computing Systems, pp 655-664

12. Folha de São Paulo (2018) Para eleitores, saúde e violência são os principais problemas do país. https://www1.folha.uol. com.br/poder/2018/09/para-eleitores-saude-e-violencia-sao-os-principais-problemas-do-pais.shtml. Accessed: .

13. Skogan W, Maxfield M (1981) Coping with crime: Individual and neighborhood reactions. Sage Publications, Beverly Hills

14. Benson P, Leffert N, Scales P, Blyth D (2012) Beyond the "village" rhetoric: creating healthy communities for children and adolescents. Appl Develop Sci 16(1):3-23

15. Fawcett S, Paine-Andrews A, Francisco V, Schultz J, Richter K, Lewis R, Williams E, Harris K, Berkley J, Fisher J (1995) Using empowerment theory in collaborative partnerships for community health and development. Am J Commun Psychol 23(5):677-697

16. Robbins S, Judge T, Sobral F (2010) Comportamento organizacional: teoria e prática no contexto brasileiro. Pearson Prentice Hall, São Paulo

17. Oliveira M, Mattedi AP, Seabra RD (2019) Social dimensions in the acceptance of and access to technology: a usability study in a collaborative security application. In: Proceedings of the 18th Brazilian Symposium on Human Factors in Computing Systems, pp 1-11

18. Landauer T (1995) The trouble with computers: usefulness, usability, and productivity. MIT Press, Massachusetts

19. Fishbein M, Ajzen I (1975) Belief, attitude, intention and behavior: an introduction to theory and research. AddisonWesley, Reading

20. Ajzen I (2011) The theory of planned behaviour: reactions and reflections. Psychology \& Health 26(9):1113-1127

21. Davis F (1989) Perceived usefulness, perceived ease of use, and user acceptance of information technology. MIS Quarterly 13(3):319-340

22. Venkatesh V, Davis F (2000) A theoretical extension of the technology acceptance model: four longitudinal field studies. Manag Sci 46(2):186-204

23. Venkatesh $\mathrm{V}$, Bala H (2008) Technology acceptance model 3 and a research agenda on interventions. Decision Sciences 39(2):273-315

24. Pavlou P (2003) Consumer acceptance of electronic commerce: integrating trust and risk with the technology acceptance model. Int J Electronic Commerce 7(3):101-134

25. Venkatesh V, Morris M, Davis G, Davis F (2003) User acceptance of information technology: toward a unified view. MIS Quarterly 27(3):425-478

26. Rogers E (2010) Diffusion of innovations. Simon and Schuster, New York

27. Van Dijk J (2006) Digital divide research, achievements and shortcomings. Poetics 34(4-5):221-235

28. International Organization for Standardization \& International Electrotechnical Commission (2001) Software Engineering Product Quality: Quality model. v. 1. ISO/IEC.

29. Alpkaya S, Sakarya C (2013) User experience transformation in telco companies: Turkcell Case. In: Marcus A (ed) Design, user experience, and usability. Web, Mobile, and Product Design. DUXU 2013. Lecture Notes in Computer Science, vol 8015. Springer, Berlin, pp 84-93

30. Preece J, Rogers Y, Sharp H (2002) Interaction design: beyond human-computer interaction. Wiley, Inc., Crawfordsville

31. Dix A, Finlay J, Abowd G, Beale R (2004) Evaluation techniques. Human-computer interaction. Pearson Education Limited, England

32. Abras C, Maloney-Krichmar D, Preece, J (2004) User-centered design. Bainbridge. W. Encyclopedia of Human-Computer Interaction 37(4): 445-456. Thousand Oaks: Sage Publications.

33. ISO 9241-11 (1998) Ergonomics of human-system interaction-Part 11: Usability: Definitions and concepts.

34. ISO 9241-11 (2018). Ergonomics of human-system interaction-Part 11: Usability: Definitions and concepts.

35. Nielsen J (1993) Usability Engineering. Morgan Kaufmann, California

36. Ayobami A S, Hector O P, Hammed A (2012) Current Issues of Usability characteristics and Usability testing. In: Proceedings of International Conference on Behavioral \& Social Science Research (ICBSSR), Kampar, Malaysia.

37. Nayebi F, Desharnais J-M, Abran A (2012) The state of the art of mobile application usability evaluation. In: Electrical \& Computer Engineering (CCECE), 25th IEEE Canadian Conference on. IEEE, pp 1-4

38. Hussain A, Saleh A, Taher A, Ahmed I, Lammasha M (2015) Usability evaluation method for mobile learning application using agile: a systematic review. Jurnal Teknologi 72(1):1-6

39. Aggarwal PK, Grover PS, Ahuja L (2019) Locating usability critical factors for mobile applications using ELECTRE-TRI Method. In: 9th International Conference on Cloud Computing, Data Science \& Engineering (Confluence), pp 596-600

40. Lewis J (1995) IBM computer usability satisfaction questionnaires: psychometric evaluation and instructions for use. Int J Hum Comput Interaction 7(1):57-78

41. Heeks R (2002) Information systems and developing countries: failure, success, and local improvisations. Information Soc 18(2):101-112

42. Kwee-Meier ST, Wiessmann M, Mertens A (2017) Integrated information visualization and usability of user interfaces for safety-critical contexts. In: International Conference on Engineering Psychology and Cognitive Ergonomics. Springer, Cham, pp 71-85

43. Pentina I, Zhang L, Bata H, Chen Y (2016) Exploring privacy paradox in information-sensitive mobile app adoption: a cross-cultural comparison. Computers in Human Behavior 65:409-419

44. Wottrich VM, van Reijmersdal EA, Smit EG (2018) The privacy trade-off for mobile app downloads: the roles of app value, intrusiveness, and privacy concerns. Decision Support Systems 106:44-52

45. Oliveira M, Mattedi AP, Seabra RD (2018) Percepções sociais sobre a adoção de aplicativos para smartphones no contexto da segurança colaborativa. In: XIV Simpósio Brasileiro de Sistemas de Informação, Caxias do Sul. Anais do XIV SBSI, pp 31-38

46. Oliveira M (2019) A influência das dimensões sociais no processo de aceitação e acesso à tecnologia: Um estudo de usabilidade de um aplicativo de segurança colaborativa. Dissertation - Federal University of Itajubá, Itajubá, p 106 (in Portuguese) 
47. Brooke J (1996) SUS - a quick and dirty usability scale. Usability Evaluation in Industry 189(194):4-7.

48. Ryu YS, Smith-Jackson TL (2006) Reliability and validity of the mobile phone usability questionnaire (MPUQ). J Usability Stud 2(1):39-53

49. Hussain A, Kutar M (2009) Usability metric framework for mobile phone application. PGNet, ISBN 2099:978-971

50. Hoehle H, Venkatesh V (2015) Mobile application usability: conceptualization and instrument development. MIS Quarterly 39(2):435-472

51. IBGE (2017) Itajubá. https://cidades.ibge.gov.br/brasil/mg/itajuba/panorama. Accessed: 24 May 2019.

52. Brasil (2016) Resolução n 510, de 07 de abril de 2016. Dispõe sobre as normas aplicáveis a pesquisas em Ciências Humanas e Sociais, Conselho Nacional de Saúde

53. Gil AC (2008) Métodos e técnicas de pesquisa social. Atlas, São Paulo

54. Günther H (2006) Pesquisa qualitativa versus pesquisa quantitativa: esta é a questão. Psicologia: teoria e pesquisa 22(2): 201-210

55. Pereira JCR (2001) Análise de dados qualitativos: estratégias metodológicas para as ciências da saúde, humanas e sociais, 3rd edn. Editora da Universidade de São Paulo, São Paulo

56. Malhotra NK (1996) Marketing research: an applied orientation. Prentice Hall, New Jersey

57. George D, Mallery P (2003) SPSS for Windows step by step: a simple guide and reference. 11.0 update, 4th edn. Allyn \& Bacon, Boston

58. Williams N (2014) 100 promising practices on safer cities: collation of urban safety practices. The Global Network on Safer Cities

\section{Publisher's Note}

Springer Nature remains neutral with regard to jurisdictional claims in published maps and institutional affiliations.

\section{Submit your manuscript to a SpringerOpen ${ }^{0}$ journal and benefit from:}

- Convenient online submission

$\checkmark$ Rigorous peer review

- Open access: articles freely available online

- High visibility within the field

- Retaining the copyright to your article

Submit your next manuscript at $\boldsymbol{\nabla}$ springeropen.com 